\title{
Bisphenol A Induces Agrp Gene Expression in Hypothalamic Neurons through a Mechanism Involving ATF3
}

\author{
Neruja Loganathan ${ }^{a}$ Emma K. Mcllwraith ${ }^{a}$ Denise D. Belsham ${ }^{a}$, b, c \\ ${ }^{a}$ Department of Physiology, University of Toronto, Toronto, ON, Canada; ${ }^{b}$ Department of Obstetrics and \\ Gynaecology, University of Toronto, Toronto, ON, Canada; ' ${ }^{\complement}$ Department of Medicine, University of Toronto, \\ Toronto, ON, Canada
}

\section{Keywords}

Bisphenol A - Activating transcription factor 3 .

Agouti-related peptide

\begin{abstract}
Background: Bisphenol A (BPA) is a ubiquitous endocrine disrupting chemical and obesogen. Although limited evidence exists of the effects of BPA on hypothalamic agoutirelated peptide (AgRP) levels, the mechanisms underlying these effects remain unknown. Given that AgRP is a potent orexigenic neuropeptide, determining the mechanism by which BPA increases AgRP is critical to preventing the progression to metabolic disease. Methods: Using quantitative reverse transcriptase polymerase chain reaction, we investigated the response of Agrp-expressing mouse hypothalamic cell lines to BPA treatment. The percentage of total BPA entering hypothalamic cells in culture was quantified using an enzyme-linked immunosorbent assay. In order to identify the mechanism underlying BPA-mediated changes in Agrp, siRNA knockdown of transcription factors, FOXO1, CHOP, ATF3, ATF4, ATF6, and small-molecule inhibitors of endoplasmic reticulum stress, JNK or MEK/ERK were used. $\boldsymbol{R e}$ sults: BPA increased mRNA levels of Agrp in six hypotha-
\end{abstract}

lamic cell lines (mHypoA-59, mHypoE-41, mHypoA-2/12, mHypoE-46, mHypoE-44, and mHypoE-42). Interestingly, only $18 \%$ of the total BPA in the culture medium entered the cells after $24 \mathrm{~h}$, suggesting that the exposure concentration is much lower than the treatment concentration. BPA increased pre-Agrp mRNA levels, indicating increased Agrp transcription. Knockdown of the transcription factor ATF3 prevented BPA-mediated increase in Agrp, pre-Agrp, and in part Npy mRNA levels. However, chemical chaperone, sodium phenylbutyrate, JNK inhibitor, SP600125, or the MEK/ERK inhibitor PD0352901 did not block BPA-induced Agrp upregulation. Conclusion: Overall, these results indicate that hypothalamic Agrp is susceptible to dysregulation by BPA and implicate ATF3 as a common mediator of the orexigenic effects of BPA in hypothalamic neurons.

(C) 2020 The Author(s)

Published by S. Karger AG, Basel

\section{Introduction}

Obesity is a pressing health concern as it leads to complications, including cardiovascular disease, diabetes, and some cancers. Although calorie-dense diets and a sedentary lifestyle are major reasons for the recent rise in obe-
(C) 2020 The Author(s)

Published by S. Karger AG, Basel

This article is licensed under the Creative Commons AttributionNonCommercial-NoDerivatives 4.0 International License (CC BYNC-ND) (http://www.karger.com/Services/OpenAccessLicense) Usage and distribution for commercial purposes as well as any distribution of modified material requires written permission.
Denise D. Belsham

Department of Physiology, University of Toronto Medical Sciences Building 3247A, 1 King's College Circle

Toronto, ON M5S 1A8 (Canada) d.belsham@utoronto.ca 
sity, the contribution of environmental endocrine disrupting chemicals, termed "obesogens," has recently gained attention $[1,2]$. Bisphenol A (BPA), a chemical widely used in polycarbonate plastics and receipt paper, has been correlated to increased body mass index and diabetes [3-6], increases body weight in rodent models [7], and has recently been classified as a metabolism-disrupting chemical [1]. BPA is detected in the urine of 9 in 10 people [4] and accumulates in tissues, including the brain [8].

Although the obesogenic effects of BPA have been primarily described as targeting fat cells, leading to adipogenesis, lipogenesis, and ultimately weight gain $[7,9,10]$, its effects on the hypothalamic control of energy homeostasis have been largely neglected. The hypothalamus houses orexigenic neuropeptide Y (NPY)/agouti-related peptide (AgRP) neurons and anorexigenic pro-opiomelanocortin (POMC) neurons that integrate peripheral indicators of energy status to maintain energy homeostasis [11]. Exogenous chemicals that affect these neurons can override this intricate control of energy balance, leading to dysregulation. In fact, maternal exposure to BPA increased protein levels of AgRP and decreased POMC in neural progenitor cells of newborn mice [12]. MacKay et al. [13] also described that in male offspring, perinatal exposure to BPA led to decreased POMC fiber innervation and increased Npy and Agrp mRNA levels when combined with a high-fat diet. The molecular mechanisms underlying these changes remained unknown, and these paradigms do not address the direct effects of BPA on neurons in the mature hypothalamus. The chronic activation of orexigenic NPY and AgRP will ultimately lead to obesity, as demonstrated with intracerebroventricular administration of the neuropeptides [11]. Notably, a single dose of AgRP was shown to increase food intake in a rodent model for 7 days, highlighting its potency [14].

We have recently described an increase in Npy, Agrp, and Pomc mRNA expression with BPA exposure in mouse hypothalamic neurons in vitro, suggesting an overall dysregulation of the hypothalamic melanocortin system beginning at the transcriptional level $[15,16]$. Mechanistically, the increase in Npy mRNA levels was mediated by the circadian transcription factor BMAL1 [15], while the transient upregulation of Pomc at $4 \mathrm{~h}$ was mediated by neuroinflammation and the transcription factor PPAR $\gamma$ [16]. However, blocking these pathways did not block the BPA-mediated upregulation in Agrp mRNA, suggesting that another distinct pathway is involved in mediating the changes in Agrp. Given that AgRP is a potent, orexigenic neuropeptide, determining the

Bisphenol A Increases Agrp mRNA through ATF3 mechanism by which BPA increases its transcription is critical to blocking the orexigenic effects of BPA.

As an orexigenic peptide, Agrp is suppressed by signals of high energy, including insulin [17], leptin [18], high glucose [19], and amino acids [20]. These signals ultimately regulate Agrp through a set of transcription factors. The understanding of the transcriptional regulation of mouse Agrp is limited, in part due to its large regulatory region that lies up to $43 \mathrm{~kb}$ upstream of its transcriptional start site [21]. Nevertheless, FOXO1 is a wellknown activator of Agrp transcription, while STAT3 directly represses Agrp transcription [18]. We therefore hypothesized that BPA increases Agrp mRNA levels by activating FOXO1 or repressing STAT3. Many other transcription factors are likely involved in the promoter regulation of Agrp. Besides circadian dysregulation and neuroinflammation, BPA has been described to induce endoplasmic reticulum (ER) stress [22]. ER stress occurs as a result of elevated protein misfolding and also in states of nutrient deprivation [23] and obesity [24], both of which are accompanied by changes in Agrp. A number of transcription factors are involved in ER stress, such as CHOP, ATF3, ATF4, and ATF6 [23], that may be involved in Agrp regulation by direct binding to the Agrp regulatory region or through interaction with other Agrpassociated transcription factors. For example, ATF3 has been previously shown to dimerize with FOXO1 on the Agrp promoter, leading to increased transcription [25]. Therefore, we also hypothesized that BPA increases Agrp mRNA levels by altering ER stress-regulated transcription factors.

Herein, we describe that BPA does indeed lead to transcriptional upregulation of Agrp mRNA in both adult and embryonic-derived mouse hypothalamic cell lines, with concurrent upregulation in the expression of Foxo1, Stat3, Chop, Atf3, Atf4, and Atf6. We further identify that the increase in Agrp is dependent on the transcription factor ATF3, yet independent of FOXO1 activation and ER stress. We also describe that ATF3 is, in part, involved in BPA-mediated Npy upregulation. Overall, these results illustrate a FOXO1-independent action of ATF3 on Agrp and Npy and highlight a common mechanism to mitigate the orexigenic effects of BPA in the hypothalamus.

\section{Methods}

Cell Culture and Reagents

Hypothalamic neurons from adult or embryonic mice were immortalized as previously described to generate several Agrpexpressing clonal cell lines [26, 27]: mHypoA-59, mHypoE-41, 
mHypoA-2/12, mHypoE-46, mHypoE-44, and mHypoE-42. Neurons were maintained in Dulbecco's modified Eagle's medium (DMEM; cat. D5796; MilliporeSigma, Oakville, ON, Canada) containing 4,500 mg/L glucose, supplemented with $2 \%$ fetal bovine serum (FBS; Gibco, Burlington, ON, Canada) and 1\% penicillin-streptomycin (PS; Gibco) at $37^{\circ} \mathrm{C}$ with $5 \% \mathrm{CO}_{2}$. Cells were split into 60 $\mathrm{mm}$ tissue culture plates approximately $24 \mathrm{~h}$ prior to treatment and grown to $75-85 \%$ confluency. Growth medium was replaced with treatment medium (as described below) on the day of treatment.

BPA (MilliporeSigma) was dissolved in $100 \%$ ethanol to a concentration $200 \mathrm{mM}$, then diluted $1: 1$ in sterile $\mathrm{H}_{2} \mathrm{O}$ to generate a $100 \mathrm{mM}$ stock solution. Vehicle $\left(50 \%\right.$ ethanol $\left.+50 \% \mathrm{H}_{2} \mathrm{O}\right)$ or $100 \mathrm{mM}$ BPA was then diluted 1:1,000 in phenol-red free DMEM (Hyclone Laboratories Inc., Whitby, ON, Canada) containing $4,500 \mathrm{mg} / \mathrm{L}$ glucose, supplemented with $1 \%$ charcoal-dextran stripped FBS (CS-FBS; Gemini Bio Products, Burlington, ON, Canada) and $1 \%$ PS, giving a final concentration of $0.05 \%$ ethanol or $100 \mu \mathrm{M} \mathrm{BPA}$ in $0.05 \%$ ethanol. For lower doses of BPA, $200 \mathrm{mM}$ $\mathrm{BPA}$ was further diluted in $100 \%$ ethanol to 100,50 , or $20 \mathrm{mM} \mathrm{BPA}$, then diluted $1: 1$ in $\mathrm{H}_{2} \mathrm{O}$, followed by $1: 1,000$ in medium to obtain final concentrations of 50, 25, and $10 \mu \mathrm{M} \mathrm{BPA}$.

Primary culture experiments were conducted as previously described [15]. Briefly, cells from the hypothalami of 8-week-old male CD-1 mice (Charles River Laboratories, Senneville, QC, Canada) were dispersed by trituration and cultured in supplemented neurobasal A medium (Thermofisher Scientific, Burlington, ON, Canada) for 7-9 days as described. Cells were treated with $0.05 \%$ ethanol or $100 \mu \mathrm{M}$ BPA for $8 \mathrm{~h}$ in phenol-red free DMEM with $1 \%$ CS-FBS and 1\% PS prior to collection for RNA isolation.

For inhibitor pretreatment experiments, pretreatments were added to the cells in $2.5 \mathrm{~mL}$ medium. BPA or ethanol was then added to the cells in $0.5 \mathrm{~mL}$ medium to achieve final concentrations of $100 \mu \mathrm{M}$ BPA or $0.05 \%$ ethanol in $3 \mathrm{~mL}$ volume. Stock solutions of actinomycin D (ActD; $10 \mathrm{mg} / \mathrm{mL})$, SP600125 (50 mM), and PD0352901 (10 mM) were prepared by dissolving in 100\% dimethyl sulfoxide, followed by a 1:1,000 dilution in medium to obtain final concentrations of $10 \mu \mathrm{g} / \mathrm{mL} \mathrm{ActD}, 50 \mu \mathrm{M}$ SP600125, and $10 \mu \mathrm{M}$ PD0352901. Sodium phenylbutyrate (PBA) was dissolved in sterile $\mathrm{H}_{2} \mathrm{O}$ to a concentration of $500 \mathrm{mM}$, followed by a $1: 100$ or 1:50 dilution into medium to obtain final concentrations of 5 and $10 \mathrm{~mm}$ PBA. ActD (cat. A1410-5MG) and PBA (cat. SML0309$100 \mathrm{MG}$ ) were purchased from MilliporeSigma, and SP600125 (cat. 1496/10) and PD0352901 (cat. 4192/10) were purchased from Tocris Bioscience (Cedarlane, Burlington, ON, Canada).

5-aminoimidazole-4-carboxamide ribonucleotide (AICAR; cat. 2840/50) was purchased from Tocris Bioscience, dissolved in $\mathrm{H}_{2} \mathrm{O}$ to $50 \mathrm{mM}$, and diluted 1:100 in medium for a final concentration of $500 \mu \mathrm{M}$. Cells were pretreated with $500 \mu \mathrm{M}$ AICAR or $\mathrm{H}_{2} \mathrm{O}$ for $1 \mathrm{~h}$, followed by $0.05 \%$ ethanol treatment for $8 \mathrm{~h}$.

\section{BPA Content Enzyme-Linked Immunosorbent Assay}

Cells were grown to $75-80 \%$ confluency in $60-\mathrm{mm}$ tissue culture plates $24 \mathrm{~h}$ prior to treatment with $0.05 \%$ ethanol, $10 \mu \mathrm{M} \mathrm{BPA}$, or $100 \mu \mathrm{M}$ BPA for 4 or $24 \mathrm{~h}$ in phenol-red free DMEM, supplemented with $1 \%$ CS-FBS and $1 \%$ PS. After treatment, $500 \mu \mathrm{L}$ of medium from each plate was collected, immediately dried down using a vacuum concentrator, and stored at $-20^{\circ} \mathrm{C}$. Cells were lysed with $500 \mu \mathrm{L} /$ plate $1 \times$ cell lysis buffer (Cell Signaling Technology Inc., New England Biolabs, Whitby, ON, Canada) diluted in phosphate-buffered saline (PBS). BPA was then collected from the cells using an ethyl acetate extraction method. Briefly, $250 \mu \mathrm{L}$ of cell lysate was acidified with $1 \mu \mathrm{L}$ of acetic acid to obtain a $\mathrm{pH}$ of $3-4$. Then, $250 \mu \mathrm{L}$ of ethyl acetate was added to each sample, vortexed, and centrifuged at $12,000 \mathrm{~g}$ for $3 \mathrm{~min}$ to separate organic and aqueous layers. The top organic layer was collected and the extraction was repeated twice using $250 \mu \mathrm{L}$ ethyl acetate each time. A total of $700 \mu \mathrm{L}$ organic layer was obtained after three extractions, which was immediately dried using compressed air and stored at $-20^{\circ} \mathrm{C}$. The Estrogen BPA Environmental ELISA Kit (cat. ab175820) was purchased from Abcam Inc. (Toronto, ON, Canada) and the assay to measure BPA content was performed as per manufacturer's instructions. A 1:50 or 1:100 dilution of each sample in sample dilution buffer was performed prior to loading samples into assay wells. Percent BPA content was calculated using the following formula: $\%$ BPA content $=[$ (content in cell lysate $) /$ (content in cell lysate + content in medium) $] \times 100$.

\section{Quantitative Reverse Transcriptase Polymerase Chain}

\section{Reaction}

Total RNA was isolated with the PureLink RNA isolation kit (Thermofisher Scientific) according to the manufacturer's instructions with genomic DNA removal using an on-column DNase step (PureLink DNase set, Thermofisher Scientific). RNA was quantified on the NanoDrop 2000 (Thermofisher Scientific) and 500$1,000 \mathrm{ng}$ of cDNA was synthesized using the Applied Biosystems High Capacity cDNA Reverse Transcription kit (Thermofisher Scientific). For the quantitative reverse transcriptase polymerase chain reaction (qRT-PCR), $12.5 \mathrm{ng}$ of $\mathrm{cDNA}$ was amplified with gene-specific primers (Table 1) and the Platinum SYBR Green qPCR SuperMix-UDG with ROX using the Applied Biosystems Prism 7900HT machine as described previously [15]. Data were analyzed with the standard curve method or with the $\Delta \Delta \mathrm{CT}$ method and normalized to the reference gene, $60 \mathrm{~S}$ ribosomal protein L7 (Rpl7).

\section{Western Blotting}

Cells were grown to $80-90 \%$ confluency in DMEM supplemented with $2 \%$ FBS and $1 \%$ PS. On the day of treatment, cells were treated with $100 \mu \mathrm{M}$ BPA or $0.05 \%$ ethanol for 2 , 4 , or $8 \mathrm{~h}$ in phenol-red free DMEM supplemented with $1 \%$ CS-FBS and $1 \%$ PS. For short-term signaling experiments, cells were serum-starved in $2.5 \mathrm{~mL}$ of phenol-red free DMEM for $1 \mathrm{~h}$ prior to treatment with $100 \mu \mathrm{M}$ BPA or $0.05 \%$ ethanol for 5,15 , or $30 \mathrm{~min}$. For AMPK signaling, on the day of treatment, $2.5 \mathrm{~mL}$ of DMEM modified phenol-red free medium with $1 \%$ CS-FBS and $1 \%$ PS was added to the cells $1 \mathrm{~h}$ prior to treatment with $100 \mu \mathrm{M}$ BPA or $0.05 \%$ ethanol for 8 h. Protein was harvested using $1 \times$ cell lysis buffer (Cell Signaling Technology Inc.) containing $1 \mathrm{mM}$ phenylmethylsulfonyl fluoride, $1 \%$ protease inhibitor cocktail, and $1 \%$ phosphatase inhibitor cocktail 2 (MilliporeSigma) and quantified using the BCA protein assay kit (Thermofisher Scientific). A total of 15-25 $\mu \mathrm{g}$ of total protein was separated on 10 or $12 \%$ SDS-polyacrylamide gels and transferred onto PVDF membranes (Bio-Rad). Membranes were blocked in 5\% milk dissolved in Tris-buffered saline with Tween 20 (TBS-T) for $1 \mathrm{~h}$, prior to incubation with primary antibody overnight at $4{ }^{\circ} \mathrm{C}$. The primary antibodies CHOP (L63F7; cat. 2895), ATF3 (D2Y5W; cat. 33593), ATF4 (D4B8; cat. 11815), ATF6 (D4Z8V; cat. 65880), a-tubulin (cat. 2144), pJNK (Thr183/ Tyr185, 81E11; cat. 4668), total JNK (cat. 9252), pERK1/2 (Thr202/ Tyr204; cat. 9101), total ERK (137F5; cat. 4695), pAMPKa (Thr172; 
Table 1. qRT-PCR primers

\begin{tabular}{|c|c|c|}
\hline Gene name & Primer sequence $\left(5^{\prime}->3^{\prime}\right)$ & Amplicon size \\
\hline \multicolumn{3}{|l|}{ qRT-PCR primers } \\
\hline Agrp & $\begin{array}{l}\text { F: CGG AGG TGC TAG ATC CAC AGA } \\
\text { R: AGG ACT CGT GCA GCC TTA CAC }\end{array}$ & 69 \\
\hline Pre-Agrp & $\begin{array}{l}\text { F: TGA CCT CAG TCC ACT GCC A } \\
\text { R: AGG ACT CGT GCA GCC TTA CAC }\end{array}$ & 139 \\
\hline Rpl7 & $\begin{array}{l}\text { F: TCG CAG AGT TGA AGG TGA AG } \\
\text { R: GCC TGT ACT CCT TGT GAT AGT G }\end{array}$ & 114 \\
\hline Foxo1 & $\begin{array}{l}\text { F: CAA AGT ACA CAT ACG GCC } \\
\text { R: GAG AGT CAG AAG TCA ACA }\end{array}$ & 147 \\
\hline Stat3 & $\begin{array}{l}\text { F: GCC ACG TTG GTG TTT CAT AAT C } \\
\text { R: TTC GAA GGT TGT GCT GAT AGA G }\end{array}$ & 97 \\
\hline Chop & $\begin{array}{l}\text { F: TAT GAG GAT CTG CAG GAG } \\
\text { R: CAG GGT CAA GAG TAG TGA AG }\end{array}$ & 109 \\
\hline Atf3 & $\begin{array}{l}\text { F: CTC CTG GGT CAC TGG TAT TTG } \\
\text { R: CCG ATG GCA GAG GTG TTT AT }\end{array}$ & 98 \\
\hline Atf4 & $\begin{array}{l}\text { F: GGA GCA AAA CAA GAC AGC } \\
\text { R: TTG CCT TAC GGA CCT CTT CT }\end{array}$ & 179 \\
\hline Atf6 & $\begin{array}{l}\text { F: CAG ATG GTG ACA ACC AGA AAG A } \\
\text { R: CAT GGA GGT GGA GGC ATA TAA AG }\end{array}$ & 112 \\
\hline Npy & $\begin{array}{l}\text { F: CAG AAA ACG CCC CCA GAA } \\
\text { R: AAA AGT CGG GAG AAC AAG TTT CAT T }\end{array}$ & 77 \\
\hline Bmal1 & $\begin{array}{l}\text { F: GGG AGG CCC ACA GTC AGA TT } \\
\text { R: GTA CCA AAG CCA ATT CAT CAA }\end{array}$ & 78 \\
\hline \multicolumn{3}{|l|}{ ChIP primers } \\
\hline FOXO1 site 1 & $\begin{array}{l}\text { F: GCA GCC ATT AAC ACT AAT GAA GC } \\
\text { R: TAC ACC TAT TTC CAT CCC CAC G }\end{array}$ & 143 \\
\hline FOXO1 site 2 & $\begin{array}{l}\text { F: GTG CCC TTG ACA AAG TTC CTG GAA } \\
\text { R: GCA GAA CCT AGG GAT GGG TCA TGC }\end{array}$ & 152 \\
\hline ATF:CRE site & $\begin{array}{l}\text { F: ATG GCA ACT GCC CCA AAC } \\
\text { R: AAG TAG TCT CCA CCC GGT T }\end{array}$ & 132 \\
\hline CEBP site & $\begin{array}{l}\text { F: TTT GAG GGA AAG GGG ATT GG } \\
\text { R: GTA AGA GCT AAT CCT AGG CGG T }\end{array}$ & 185 \\
\hline ATF3 on ATF3 promoter & $\begin{array}{l}\text { F: CCA GTT CTC CTG GAA GCT A } \\
\text { R: CGT TGC ATC ACC CCT TTT AA }\end{array}$ & 110 \\
\hline
\end{tabular}
tion.

ChIP, chromatin immunoprecipitation; qRT-PCR, quantitative reverse transcriptase polymerase chain reac-

cat. 2532S), and total AMPKa (cat. 2535S) were purchased from Cell Signaling Technology Inc. and were diluted 1:1,000 in 5\% milk in TBS-T (for CHOP, JNK, ERK, AMPK) or in 5\% bovine serum albumin in TBS-T. Membranes were washed and incubated with secondary HRP-linked antimouse (for CHOP) or antirabbit antibody $(1: 7,500$ in $5 \%$ milk in TBS-T; Cell Signaling Technology
Inc.) for $1 \mathrm{~h}$, washed, and imaged using the Signal Fire ECL Reagent (Cell Signaling Technology Inc.) on the Kodak Image Station 2000R. The Restore PLUS Western blot stripping buffer (Thermofisher Scientific) was used according to the manufacturer's instructions before probing the same blot for subsequent proteins. Protein density was quantified using ImageJ. 
Table 2. siRNA duplex sequences

\begin{tabular}{lll}
\hline Gene target & siRNA duplex sequence $\left(5^{\prime}->3^{\prime}\right)$ & Target region \\
\hline Foxo1 & mm.Ri.Foxo1.13.3 & exon 2 \\
& CUU CUG GAU AAU CUC AAC CUU CUC T & \\
& AGA GAA GGU UGA GAU UAU CCA GAA GGU & exon $3 / 4$ \\
\hline Chop & mm.Ri.Ddit3.13.3 & \\
& AAC AGA GGU CAC ACG CAC AUC CCA A & exon 2 \\
\hline Atf3 & mm.Ri.Atf3.13.3 & \\
& CUG GAG UCA GUU ACC GUC AAC A & exon $3 / 4$ \\
& UGU UGA CGG UAA CUG ACU CCA GCG & \\
\hline Atf6 & AAG ACU GAG AAA UUG GAU AAG C & exon 15 \\
& GCU UCU UAU CCA AUU UCU CAG UCU UCA & \\
\hline
\end{tabular}

\section{siRNA Knockdown}

Cells were grown to $75-80 \%$ confluency in $100-\mathrm{mm}$ tissue culture plates for transfection. siRNA duplexes (Table 2) and negative control (cat. 51-01-14-03) were purchased from Integrated DNA Technologies Inc. (Coralville, IA, USA). A total of $25 \mathrm{nM}$ of siRNA or negative control and $25 \mu \mathrm{L} /$ plate of Dharmafect 3 Transfection Reagent (Dharmacon; Cedarlane) were complexed for $20 \mathrm{~min}$ at room temperature in serum- and antibiotic-free DMEM (cat. D5796; MilliporeSigma). The complexed reagents were diluted in $2 \%$ FBS containing antibiotic-free DMEM. Cells were incubated with $5 \mathrm{~mL} /$ plate of transfection medium for $24 \mathrm{~h}$. The cells were then washed with PBS and treated with $100 \mu \mathrm{M}$ BPA or $0.05 \%$ ethanol for $8 \mathrm{~h}$ in antibiotic-free phenol-red free DMEM containing $1 \%$ CS-FBS. Cells were lysed and RNA and protein were collected from the same plate using the mirVANA PARIS kit (Thermofisher Scientific) to measure changes in mRNA and protein levels as described above. For the Foxo1 siRNA experiments, siRNA knockdown was validated with qRT-PCR as an appropriate antibody was not available.

\section{Promoter Analysis and Chromatin Immunoprecipitation}

The mouse Agrp regulatory region was obtained, and the transcriptional start site was inferred from previously published papers on the Agrp promoter [18]. ATF:CRE (TGACGTCA) and CEBP (TG(T/A)TGCAAT) sites were manually identified [28].

mHypoA-59 cells were grown to $80-85 \%$ confluency in $100-\mathrm{mm}$ tissue culture plates for treatment. Cells were treated with $100 \mu \mathrm{M}$ BPA or $0.05 \%$ ethanol for 1,4 , or $8 \mathrm{~h}$. An additional plate of cells was treated with $0.05 \%$ ethanol (vehicle) per experimental replicate for immunoprecipitation (IP) with the negative control (normal rabbit IgG) antibody. Cells were harvested in PBS containing $1 \times$ protease inhibitor cocktail, and chromatin IP (ChIP) was performed using the SimpleChIP Enzymatic Chromatin IP kit with magnetic beads (Cell Signaling Technology Inc.) according to the manufacturer's instructions. Two micro- grams of ATF3 antibody (D2Y5W, cat. 33593, Cell Signaling Technology Inc.) or normal rabbit IgG antibody (provided with the kit) were used for the IP. DNA was purified using columns provided with the SimpleChIP kit or the PureLink PCR Purification Kit (Thermofisher Scientific). Binding of ATF3 to the Agrp promotor region was analyzed using $\mathrm{qRT}$-PCR with cycling conditions as described previously [15]. Each sample was run in triplicate using 3.5 $\mu \mathrm{L}$ of purified DNA in $10 \mu \mathrm{L}$ reactions with primers specific for the Agrp promotor or the Atf3 promoter (Table 1) and the Platinum SYBR Green qPCR SuperMix-UDG with ROX. The mean cycle of threshold (CT) of each IP sample and its respective $2 \%$ input sample were used to calculate the percent of DNA pulled down by the antibody relative to input: $\%$ of input = $2 \% \times 2^{\text {(CT } 2 \% \text { input sample }- \text { CT IP sample) }}$. Relative binding was calculated by taking the average of the percent inputs of vehicle and treated groups per experimental replicate and dividing each value by the respective average.

\section{Statistical Analysis}

Data were analyzed for statistical significance using GraphPad Prism 6.0 (GraphPad Prism Software Inc., San Diego, CA, USA). Student $t$ test, one-way ANOVA, or two-way ANOVA, followed by the Bonferroni or Tukey multiple comparison test, were performed as appropriate and are indicated in the figure legends. Differences were considered statistically significant when $p$ was $<0.05$. Data are presented as mean \pm SEM, with statistical significance denoted as $* p<0.05,{ }^{* *} p<0.01,{ }^{* * *} p<0.001$, and ${ }^{* * * *} p<0.0001$ when comparing vehicle- versus BPA-treated groups, as ${ }^{\#} p<0.05$,

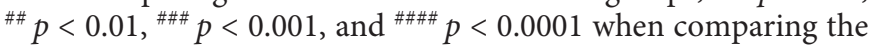
effect of inhibitor pretreatments or siRNA knockdowns within vehicle- or BPA-treated groups, and as ${ }^{+} p<0.05,{ }^{++} p<0.01$, ${ }^{++} p<0.001$, and ${ }^{++++} p<0.0001$ when comparing the interaction between two factors. $n$ values refer to independent experimental replicates. 


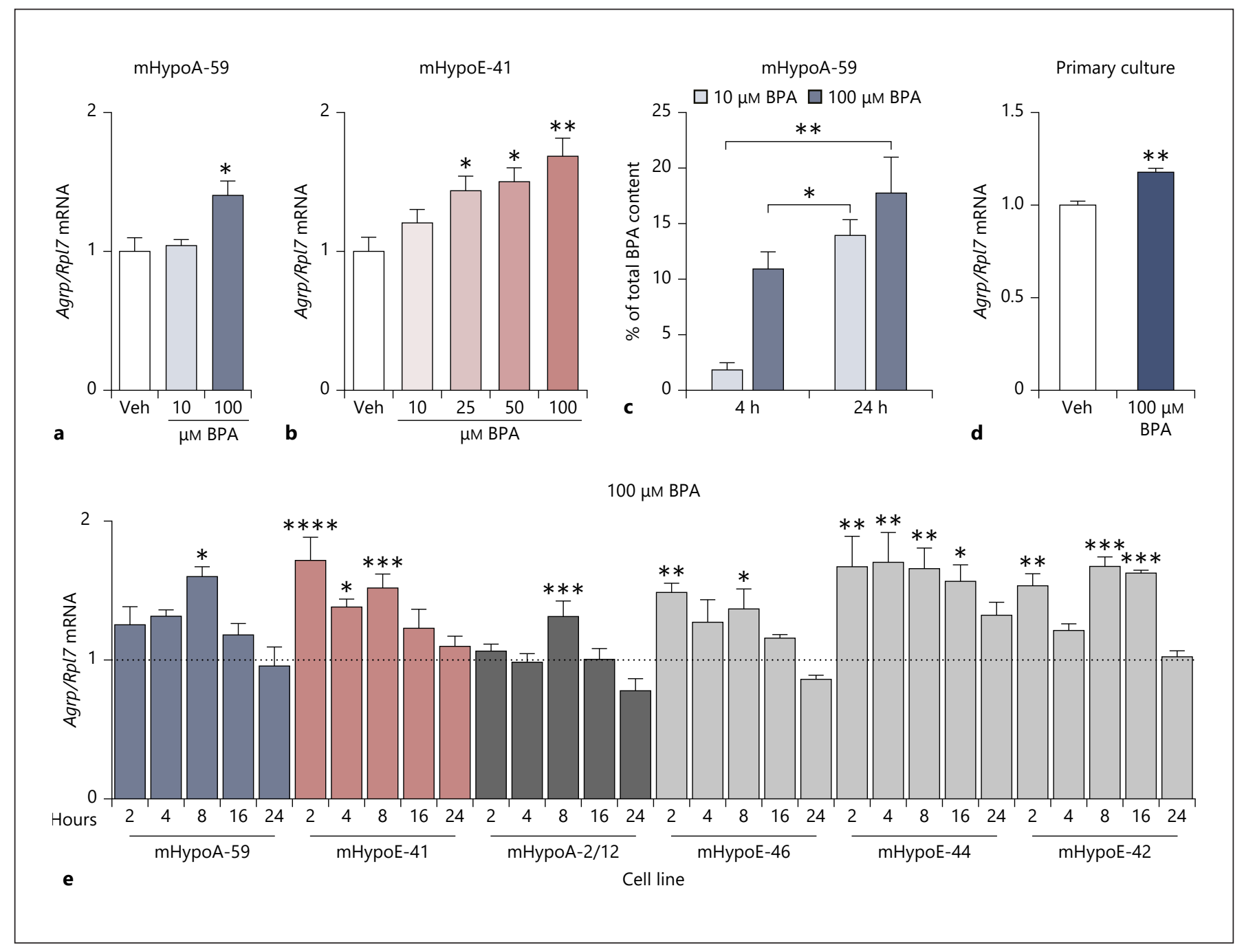

Fig. 1. BPA increases Agrp mRNA expression in hypothalamic cell lines. a mHypoA-59 cells treated with 10 or $100 \mu \mathrm{M}$ BPA or vehicle $(0.05 \%$ ethanol) for $4 \mathrm{~h}(n=3)$. b mHypoE- 41 cells treated with 10 , 25,50 , or $100 \mu \mathrm{M}$ BPA or vehicle for $4 \mathrm{~h}(n=4)$. c mHypoA-59 cells treated with 10 or $100 \mu \mathrm{M} \mathrm{BPA}$ or vehicle for 4 or $24 \mathrm{~h}$, followed by collection of both cells and media to determine BPA content $(n=$ 3-4). d Primary culture derived from the hypothalamus of male CD-1 mice treated with $100 \mu \mathrm{M}$ BPA or vehicle for $8 \mathrm{~h}(n=4)$. e Six Agrp-expressing cell lines treated with $100 \mu \mathrm{M}$ BPA or vehicle for $2,4,8,16$, or $24 \mathrm{~h}(n=3-6)$. Time-matched vehicles are repre-

\section{Results}

\section{BPA Increases Agrp mRNA Levels in Several \\ Hypothalamic Cell Lines}

To characterize the effects of BPA and establish the optimal treatment dose, adult-derived mHypoA-59 cells were treated with 10 or $100 \mu \mathrm{M} \mathrm{BPA}$ for $4 \mathrm{~h} ; 100 \mu \mathrm{M} \mathrm{BPA}$ increased Agrp expression in mHypoA-59 cells (Fig. 1a), sented by the dotted line at $y=1$ and asterisks indicate significant difference compared with the time-matched vehicle. Agrp gene expression was analyzed using qRT-PCR. Data are expressed as mean \pm SEM, and statistical significance was determined using Student $t$ test (d), one-way ANOVA (a, b), or two-way ANOVA (c, e), followed by Bonferroni post hoc test $(\mathbf{a}, \mathbf{b}, \mathbf{e})$ or Tukey multiple comparison test (c). ${ }^{*} p<0.05,{ }^{* *} p<0.01,{ }^{* * *} p<0.001$, ${ }^{* * * *} p<0.0001$. BPA, bisphenol A; qRT-PCR, quantitative reverse transcriptase polymerase chain reaction. while $10 \mu \mathrm{M}$ BPA did not alter Agrp expression in the embryonic-derived mHypoE-41 cells; however, 25, 50, and $100 \mu \mathrm{M}$ BPA increased Agrp mRNA in this cell line (Fig. 1b). These results suggested that BPA does act as an orexigen in both adult- and embryonic-derived hypothalamic neurons, albeit at a higher concentration than what is reported in humans $[29,30]$. 
For this reason, we aimed to determine the amount of BPA that was able to enter the neurons in culture. BPA may not readily dissolve in aqueous culture medium and enter cells due to its lipophilic nature [31]. To determine the percentage of BPA in the medium that enters hypothalamic neurons, an enzyme-linked immunosorbent assay was performed to determine the concentration of BPA within the cells and in the culture medium 4 and $24 \mathrm{~h}$ after treatment. At $4 \mathrm{~h}, 2$ and $10 \%$ of the total measured BPA was found within the cells when treated with 10 and $100 \mu \mathrm{M} \mathrm{BPA}$, respectively, or an equivalent concentration of $200 \mathrm{nM}$ and $10 \mu \mathrm{M}$. At $24 \mathrm{~h}, 14 \%$ with the $10-\mu \mathrm{M}$ treatment and $18 \%$ with the $100-\mu \mathrm{M}$ treatment of the total BPA content was found within the cells (1.4 and $18 \mu \mathrm{M}$; Fig. 1c). Thus, only a fraction of the BPA that is dissolved into the culture medium actually enters the hypothalamic cell, indicating a lower exposure concentration than the apparent treatment concentration. Furthermore, with lower treatment concentration, there is a lower percentage of entry into the cells. Accordingly, when mHypoA-59 cells were treated with 10 and $100 \mu \mathrm{M} \mathrm{BPA}$ (Fig. 1a), only the higher apparent concentration of 100 $\mu \mathrm{M}$ was able to increase Agrp expression. We therefore chose to use $100 \mu \mathrm{M}$ BPA in our subsequent experiments to ensure adequate and consistent entry of BPA into hypothalamic cells in culture.

Treatment with $100 \mu \mathrm{M}$ BPA for $8 \mathrm{~h}$ in hypothalamic primary culture derived from 8 -week-old male mice (Fig. 1d) and in six hypothalamic cell lines from 2 to $24 \mathrm{~h}$ (Fig. 1e) revealed consistent upregulation of Agrp across cell models, again illustrating the orexigenic nature of BPA across an array of AgRP neurons. In embryonic-derived cell lines (mHypoE-), the upregulation occurred from as early as $2 \mathrm{~h}$ until 8 or $16 \mathrm{~h}$, whereas in adult cell lines (mHypoA-), Agrp was significantly upregulated at $8 \mathrm{~h}$ alone (Fig. 1e).

Fig. 2. BPA increases pre-Agrp mRNA levels and associated transcription factors. a, b mHypoA-59 (a) or mHypoE-41 cells (b) pretreated with transcriptional inhibitor $10 \mu \mathrm{g} / \mathrm{mL}$ ActD or $0.1 \%$ DMSO for $1 \mathrm{~h}$, followed by treatment with $100 \mu \mathrm{M}$ BPA or vehicle $(0.05 \%$ ethanol) for $8 \mathrm{~h}(n=4)$. c Schematic of the locations of primers used to amplify mature Agrp and pre-Agrp using qRTPCR. d-f mHypoA-59 or mHypoE-41 cells treated with $100 \mu \mathrm{M}$ BPA or vehicle for 2,4 , or $8 \mathrm{~h}$ (same samples as in Fig. $1 \mathrm{e} ; n=3-5$ ). Time-matched vehicles are represented by the dotted line at $y=1$ and asterisks indicate significant difference compared with the time-matched vehicle. Gene expression was analyzed using qRTPCR. g, h mHypoA-59 cells treated with $100 \mu \mathrm{M}$ BPA or vehicle for 2 , 4 , or $8 \mathrm{~h}$ for protein quantification $(n=3-4$ for CHOP, $n=$

\section{BPA Increases Transcription of Agrp mRNA and} Associated Transcription Factors

The mechanism underlying BPA-induced Agrp expression may be a result of transcription factor binding and transcriptional activation at the promotor level, or a result of increased stability of the transcript if there is no de novo transcription occurring. To test this, the transcriptional inhibitor ActD was used prior to treatment with BPA. ActD decreased basal and BPA-induced levels of Agrp at $8 \mathrm{~h}$ in the mHypoA-59 and mHypoE-41 cell lines, indicative of the inhibition of de novo Agrp transcription and subsequent mRNA degradation. Furthermore, in the presence of ActD, BPA did not increase Agrp mRNA levels compared to vehicle, suggesting that transcription is required for the BPA-induced upregulation of Agrp (Fig. 2a, b). To determine whether Agrp itself is regulated at the transcriptional level, changes in a region containing an intronic portion of Agrp (pre-mRNA) were measured (Fig. 2c). The expression of pre-Agrp mRNA was upregulated by BPA at $2 \mathrm{~h}$ in the mHypoA-59 cells (Fig. $2 \mathrm{~d}$ ) and at 2 and $8 \mathrm{~h}$ in the mHypoE-41 cells (Fig. 2e), suggesting de novo transcription of Agrp.

Given that BPA increases transcription of Agrp, we hypothesized that the mechanism of BPA action depends on one or more transcription factors that regulate Agrp at the promoter level.

We took two approaches to answer this question. First, we investigated transcription factors that are known to regulate Agrp: Foxo1, and Stat3 [18]. Second, we had previously found that BPA-induced pathways, including circadian dysregulation and neuroinflammation, did not mediate its effects on Agrp. ER stress is often activated by BPA [22] and is tightly linked to hypothalamic dysregulation seen in obesity [24]. Furthermore, ER stress activates a myriad of transcription factors that may directly activate Agrp transcription or interact with Agrp-activating transcription factors [23]. As such, we first determined

2 for ATF3). Protein levels were analyzed using Western blotting and representative blots from one experimental replicate are shown. No bands for CHOP or ATF3 appeared in vehicle-treated samples, thus only BPA-treated samples were quantified by densitometry. Data are expressed as mean \pm SEM (except for $\mathbf{h}$ ), and statistical significance was determined using two-way ANOVA followed by Tukey multiple comparison test $(\mathbf{a}, \mathbf{b})$ or Bonferroni post hoc test (d-f) or one-way ANOVA followed by Bonferroni post hoc test (g). Vehicle versus BPA: ${ }^{*} p<0.05,{ }^{* *} p<0.01,{ }^{* * *} p<$ $0.001,{ }^{* * * *} p<0.0001$; DMSO versus ActD: ${ }^{\# \#} p<0.01,{ }^{\# \#} p<0.001$, $\# \# \#<0.0001$; interaction: ${ }^{++} p<0.01$. ActD, actinomycin D; BPA, bisphenol A; DMSO, dimethyl sulfoxide; qRT-PCR, quantitative reverse transcriptase polymerase chain reaction.

(For figure see next page.) 

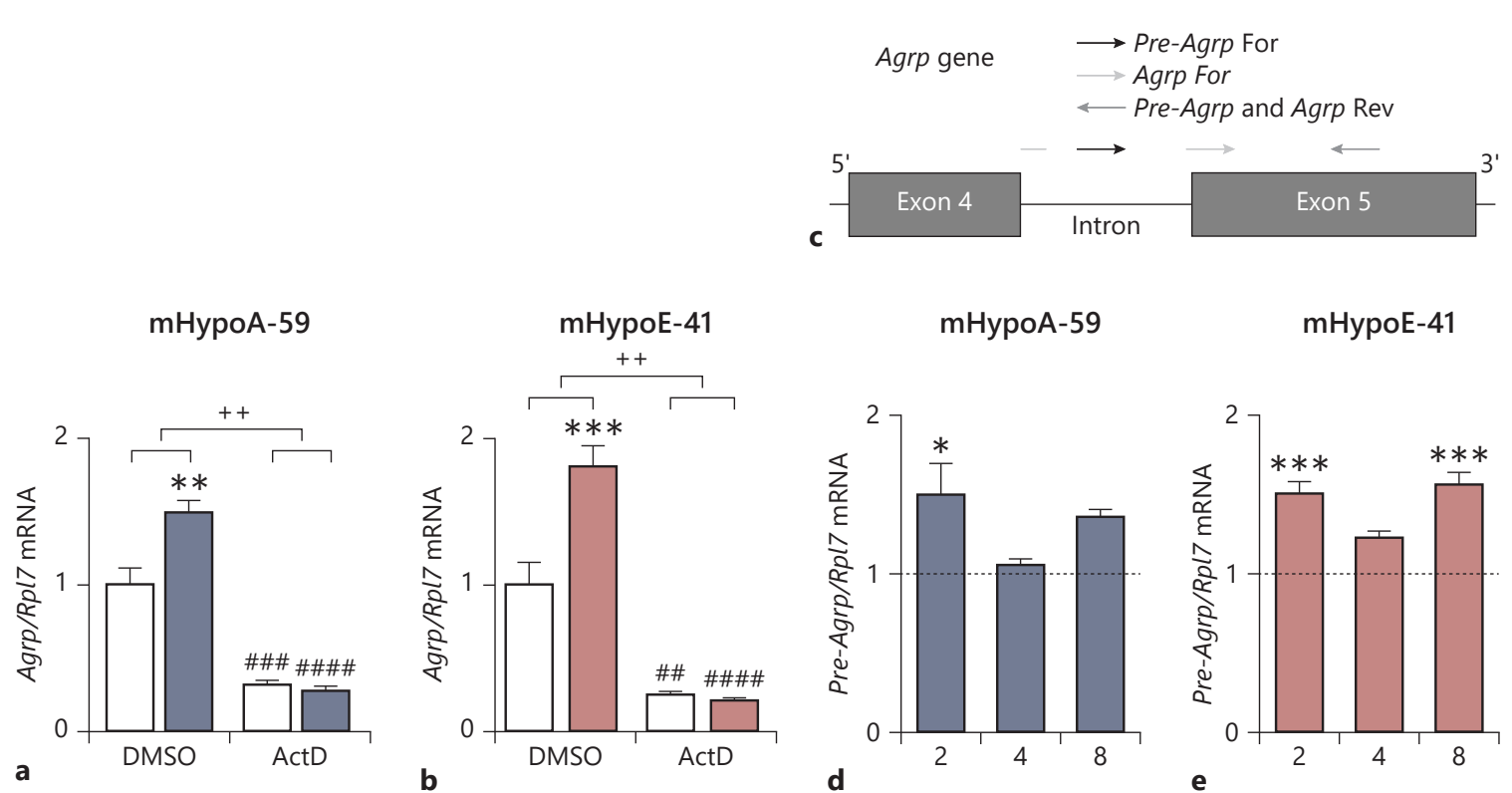

mHypoA-59

mHypoE-41
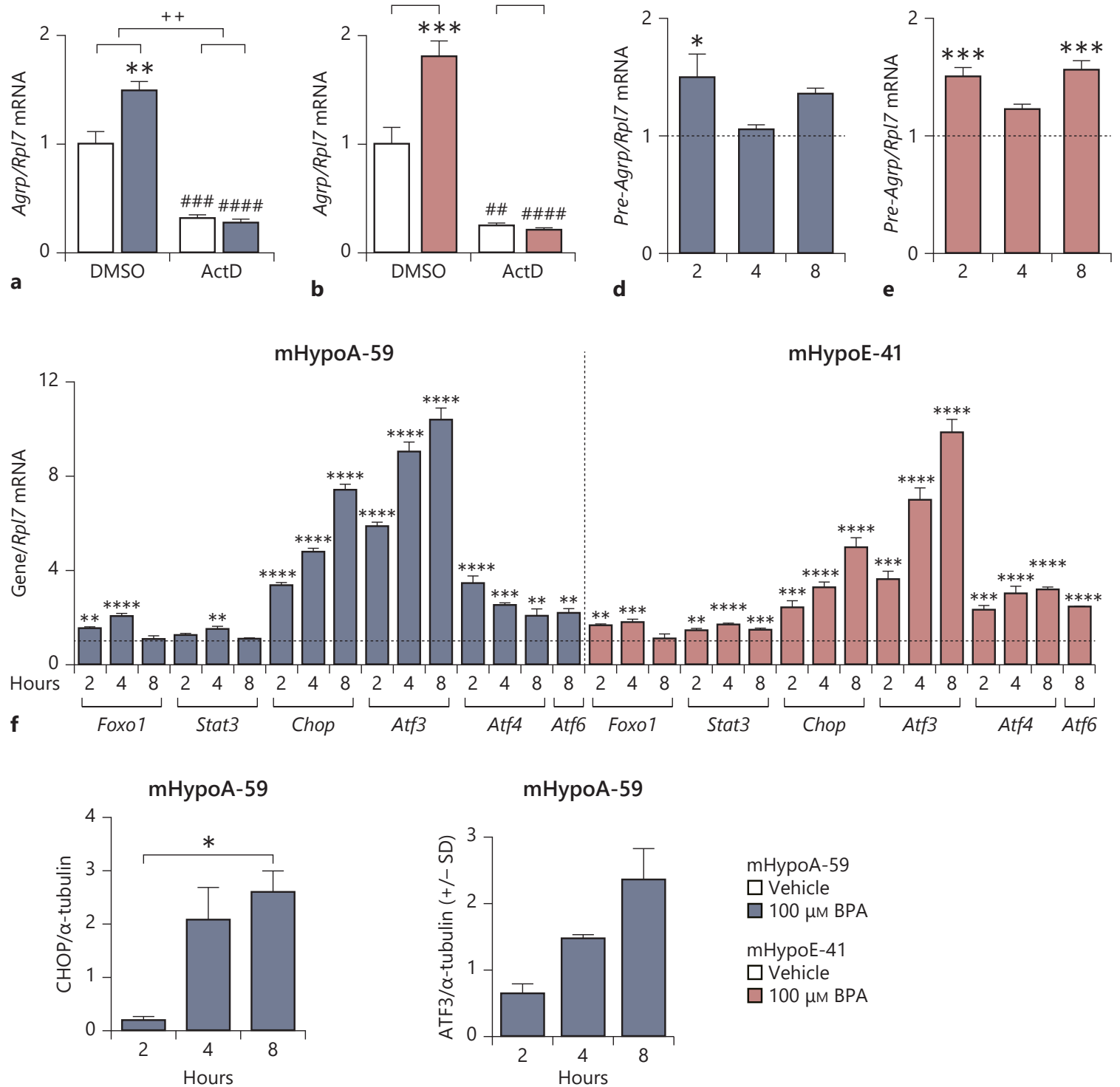

HypoA-59

mHypoE-41
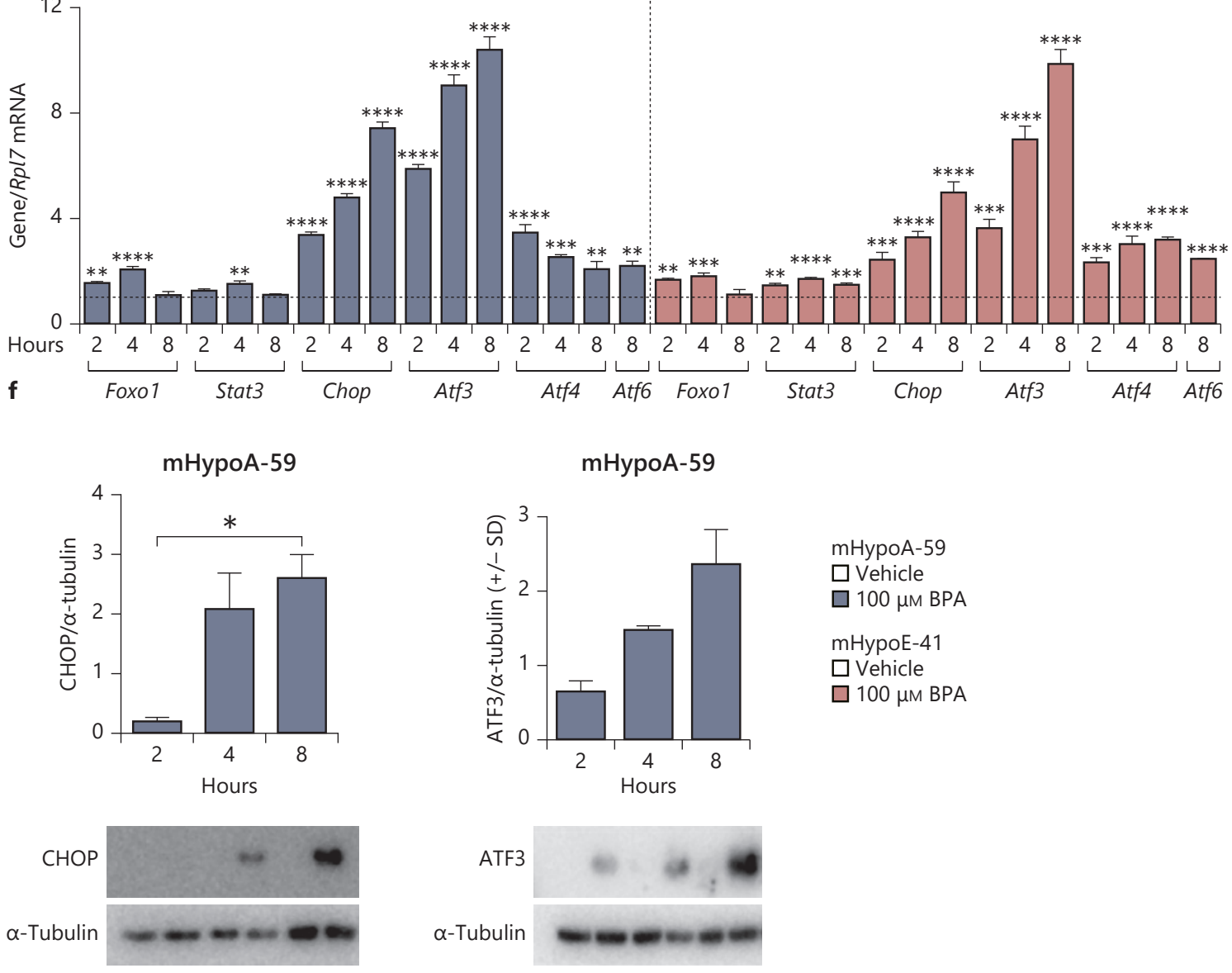

ATF3

$\alpha$-Tubulin

g

BPA - + - + - +

h $\mathrm{BPA}-+-++$

mHypoA-59

$\square$ Vehicle

$\square 100 \mu \mathrm{M} \mathrm{BPA}$

mHypoE-41

$\square$ Vehicle

$\square 100 \mu \mathrm{M}$ BPA 
whether these transcription factors are altered with BPA treatment. In both the mHypoA-59 and mHypoE-41 cells, Foxo 1 and Stat 3 as well as the stress-responsive transcription factors Chop, Atf3, Atf4, and Atf6 were increased with $100 \mu \mathrm{M}$ BPA treatment from 2 to $8 \mathrm{~h}$ (Fig. 2f). Atf 3 and Chop had the greatest fold change of approximately 10-fold (both cell lines) and 8- or 5-fold (mHypoA-59 and $\mathrm{mHypoE}-41$, respectively) at $8 \mathrm{~h}$ (Fig. 2f). The protein levels of both CHOP and ATF3 were also increased, indicating their potential to bind to and alter transcription at the promoter level (Fig. 2g, h). As Stat3 levels were only modestly increased, rather than decreased as would have been expected from previous studies [18], we did not follow up on the potential role of this transcription factor in BPA-mediated Agrp upregulation.

Knockdown of ATF3 Blocks the BPA-Induced Increase in Agrp and pre-Agrp $m R N A$

To determine whether the BPA-mediated increase in Agrp was dependent on any of the above-mentioned transcription factors, siRNA-mediated knockdown was performed (Fig. 3a), and the transcription and translation of each transcription factor was significantly decreased with siRNA exposure. Knockdown of ATF3 in the mHypoA-59 cells increased basal expression of Agrp, but blocked an increase in Agrp with BPA (Fig. 3b), suggesting that ATF3 is necessary for the BPA-mediated orexigenic effect. Interestingly, knockdown of FOXO1, CHOP, ATF4, and ATF6 did not prevent the upregulation of Agrp by BPA (Fig. 3b). ATF3 knockdown also prevented BPA-mediated Agrp induction in the embryonic-derived mHypoE-41 cell line (Fig. 3c, d). Similar results were seen with pre-Agrp mRNA (Fig. 3e), suggesting that ATF3 is required for BPA-induced de novo transcription of Agrp.

\section{BPA Does Not Increase ATF3 Binding to Agrp Regulatory Elements}

ATF3 is a transcription factor that can either bind ATF:CRE elements or dimerize with other transcription

Fig. 3. ATF3 knockdown prevents BPA-mediated increase in Agrp and pre-Agrp mRNA. a, b, e mHypoA-59 cells transfected with siRNA duplexes targeting Foxo1, Chop, Atf3, Atf4, or Atf6 or negative control (NC) for $24 \mathrm{~h}$, followed by treatment with $100 \mu \mathrm{M}$ BPA or vehicle ( $0.05 \%$ ethanol) for $8 \mathrm{~h}(n=3-5)$. c-e mHypoE-41 cells transfected with a siRNA duplex targeting Atf 3 or NC for $24 \mathrm{~h}$, followed by treatment with $100 \mu \mathrm{M}$ BPA or vehicle for $8 \mathrm{~h}$ $(n=6)$. siRNA knockdown of the various transcription factors (a) or ATF3 (c) was confirmed using qRT-PCR and Western blotting prior to analyzing changes in $\operatorname{Agrp}(\mathbf{b}, \mathbf{d})$ or pre-Agrp factors, including FOXO1, CEBP $\beta$, p53, and CREB among several others [28]. The ATF3:FOXO1 dimer has been previously validated to bind to and increase transcription of Agrp in response to low glucose conditions [25]. Alternatively, ATF:CRE, AP1, and CEBP sites were found to be the most common ATF3 binding sites in the entire genome [28]. Several AP1 binding sites are present in the Agrp regulatory region. We identified a potential ATF:CRE (TGACGTCA) and a potential CEBP (TGTTGCAAT) site in the distal regulatory region of Agrp (Fig. 4a).

ChIP experiments revealed that increased ATF3 binding to the previously validated FOXO1 binding sites on Agrp did not occur with $100 \mu \mathrm{M}$ BPA treatment for 1 or $4 \mathrm{~h}$ (Fig. 4b, c). Relative binding of ATF3 was greater than IgG at the ATF:CRE site at $1 \mathrm{~h}$, suggesting a basal degree of ATF3 binding to this region. However, BPA did not increase ATF3 binding at the ATF:CRE site or the CEBP site in the Agrp distal regulatory region (Fig. 4b). Thus, an alternative binding site within the large 43-kb Agrp promoter is likely involved. ATF3 is known to bind to its own promoter, which was thus used as a positive control for the antibody with previously validated primers [32]. With 4 or $8 \mathrm{~h}$ of BPA treatment, ATF3 binding to the ATF3 promoter was increased (Fig. 4c).

\section{BPA Induces ER Stress, JNK, ERK, and AMPK, but}

Does Not Require ER Stress, JNK, or ERK to Increase

Agrp $m R N A$

The factors upstream of ATF3, leading to its induction and ultimately the increase in Agrp, remain unknown. Treatment with ActD suggests that transcription of (a) gene(s) is required for the increase in Atf3 (Fig. 5a). MAP kinases and ER stress are well-characterized regulators of ATF3, with ATF4 being the transcription factor directly upstream of ATF3 in the ER stress pathway $[33,34]$. Interestingly, in the mHypoA-59 cells, although ATF4 knockdown decreased the basal levels of ATF3, it did not prevent the BPA-mediated increase in

(e) mRNA levels using qRT-PCR. Representative blots from one experimental replicate of the siRNA knockdown validation are shown below the qRT-PCR validation $(\mathbf{a}, \mathbf{c})$. Data are expressed as mean \pm SEM, and statistical significance was determined using two-way ANOVA followed by the Tukey multiple comparison test (a-e). Vehicle versus BPA: ${ }^{*} p<0.05,{ }^{* *} p<0.01,{ }^{* * *} p<0.001$, **** $p<0.0001$; NC versus siRNA: ${ }^{\#} p<0.05,{ }^{\# \#} p<0.01$, \#\#\#\# $p<$ 0.0001 ; interaction: ${ }^{+} p<0.05,{ }^{++} p<0.01,{ }^{+++} p<0.001,{ }^{+++} p<$ 0.0001 . BPA, bisphenol A; qRT-PCR, quantitative reverse transcriptase polymerase chain reaction.

(For figure see next page.) 


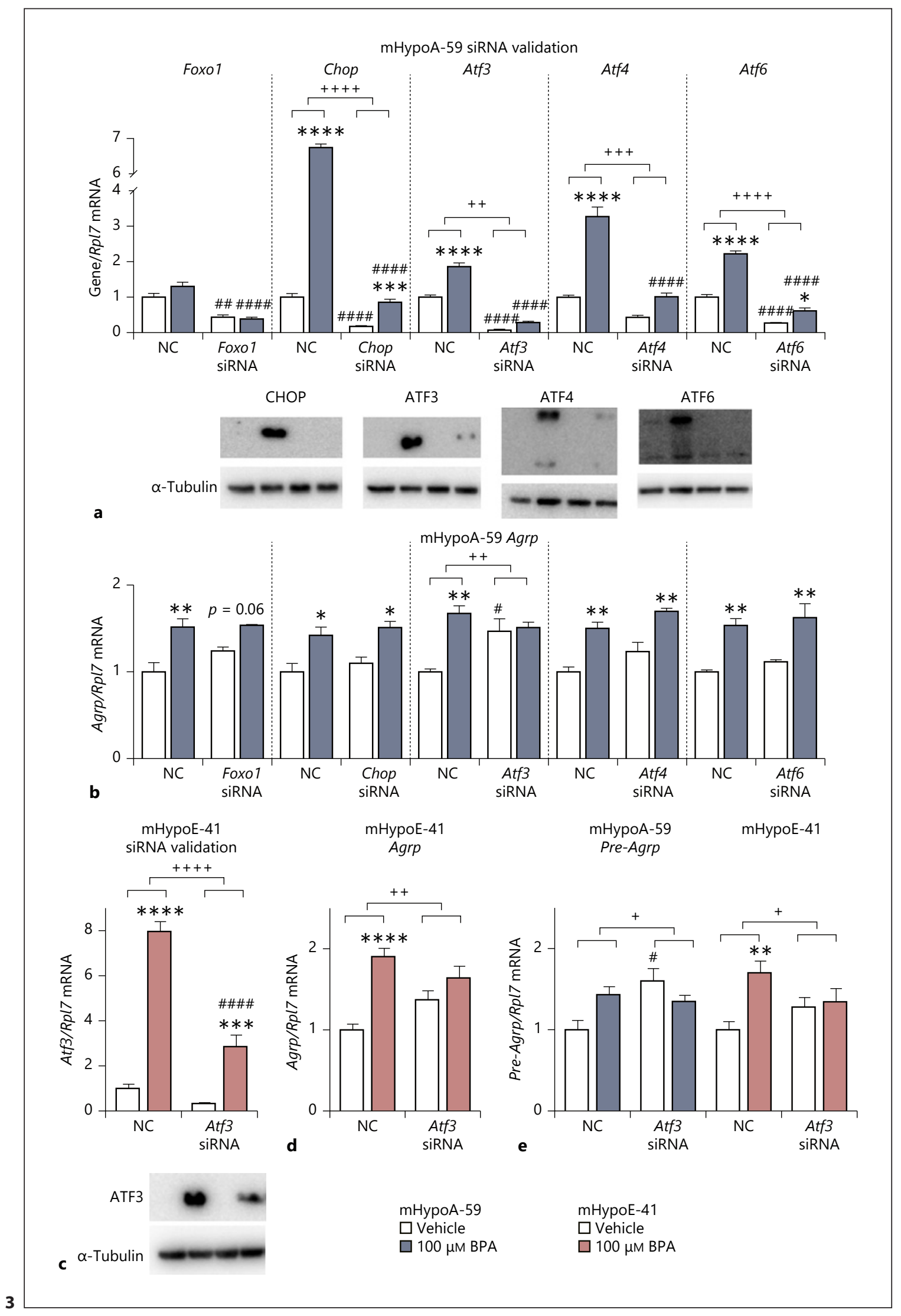


ATF3 (Fig. 5b), suggesting that akin to Agrp (Fig. 3b), BPA acts independently of ATF4 to upregulate Atf3. We next investigated whether common upstream regulators of ATF3 may mediate the BPA-induced changes in Agrp. As BPA induces ER stress (Fig. 2f), we used the generalized chemical chaperone PBA to mitigate ER stress.
However, PBA did not significantly abolish the BPAmediated upregulation of Agrp (Fig. 5c), suggesting that this effect is independent of ER stress. The MAP kinases JNK and ERK were also induced with BPA (Fig. 5d, e, g), but inhibition of each using SP600125 (JNK) or PD0352901 (ERK) did not block the increase in Agrp

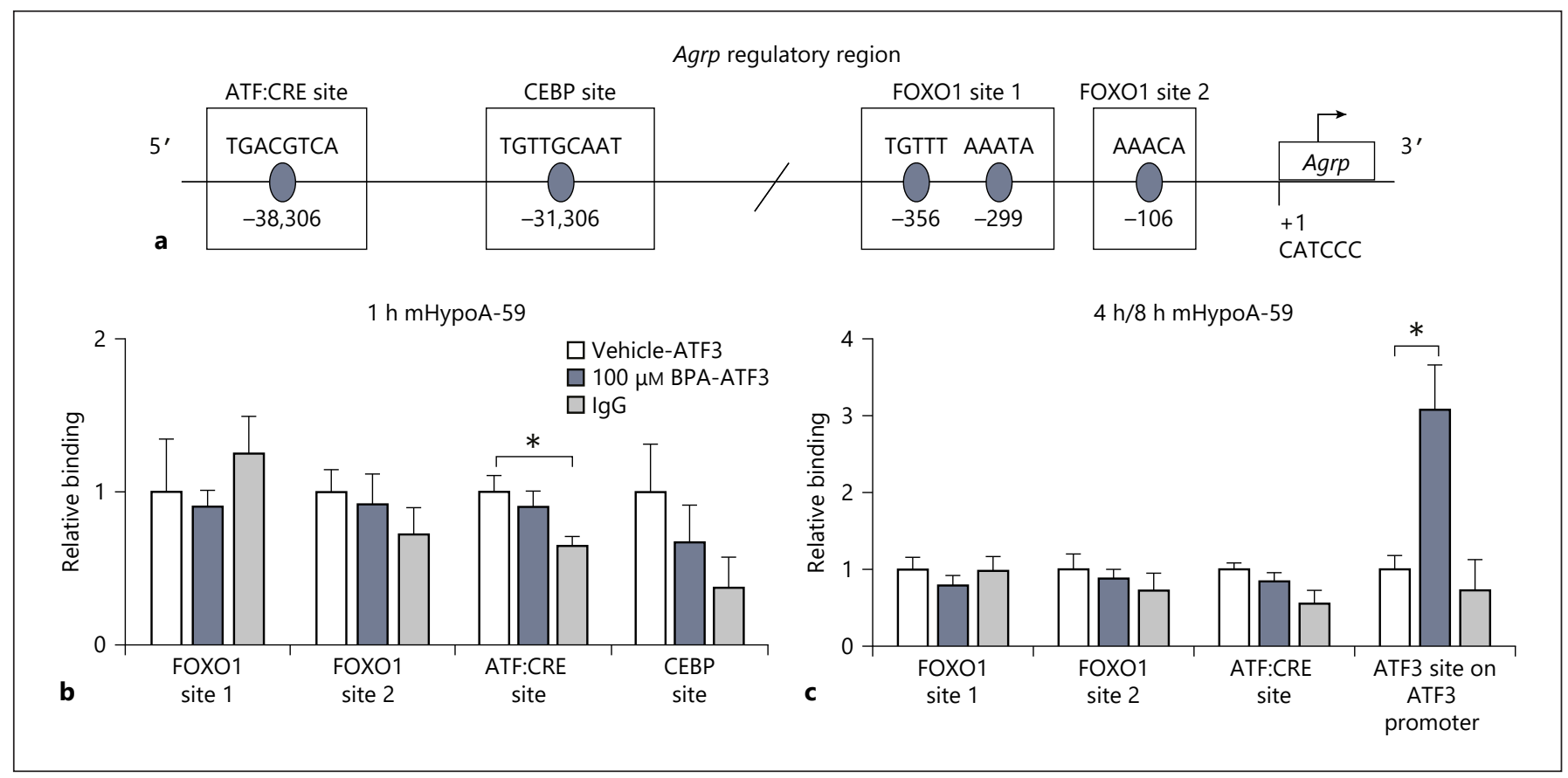

Fig. 4. BPA does not increase ATF3 binding to specific Agrp regulatory regions. a Schematic of transcription factor binding sites in the Agrp regulatory region. Circles and sequences represent potential ATF3 binding sites. Boxes represent the sites encompassed by each primer pair used for $\operatorname{ChIP}(\mathbf{b}, \mathbf{c})$. b, $\mathbf{c}$ mHypoA-59 cells treated with $100 \mu \mathrm{M}$ BPA or vehicle $(0.05 \%$ ethanol) for $1 \mathrm{~h}(n=3-5$; $\mathbf{b})$ or $4 \mathrm{~h}$ $(n=3 ; \mathbf{c})$, followed by ChIP with an ATF3 antibody or IgG. Samples

Fig. 5. BPA induces ER stress, JNK, ERK, and AMPK, but does not require ER stress, JNK, or ERK to increase Agrp mRNA. a mHypoA-59 or $\mathrm{mHypoE}-41$ cells pretreated with transcriptional inhibitor $10 \mu \mathrm{g} / \mathrm{mL}$ ActD or $0.1 \%$ DMSO for $1 \mathrm{~h}$, followed by treatment with $100 \mu \mathrm{M}$ BPA or vehicle $(0.05 \%$ ethanol) for $8 \mathrm{~h}$ $(n=4)$. b mHypoA-59 cells transfected with a siRNA duplex targeting Atf4 or negative control (NC) for $24 \mathrm{~h}$, followed by treatment with $100 \mu \mathrm{M}$ BPA or vehicle for $8 \mathrm{~h}(n=3)$. c mHypoA-59 or mHypoE-41 cells pretreated with $\mathrm{H}_{2} \mathrm{O}, 5 \mathrm{~mm} \mathrm{PBA}$, or $10 \mathrm{~mm} \mathrm{PBA}$ for $1 \mathrm{~h}$ prior to treatment with $100 \mu \mathrm{M}$ BPA or vehicle for $8 \mathrm{~h}$. d, e mHypoA-59 (d) and mHypoE-41 cells (e) serum starved for $1 \mathrm{~h}$ and treated with vehicle, $10 \mu \mathrm{M} \mathrm{BPA}$, or $100 \mu \mathrm{M}$ BPA for 15 or 30 min. f, h mHypoA-59 or mHypoE-41 cells pretreated with $0.1 \%$ DMSO or $50 \mu \mathrm{M}$ SP600125 (SP; JNK inhibitor) (f) or $0.1 \%$ DMSO or $10 \mu \mathrm{M}$ PD0352901 (PD; MEK/ERK inhibitor) (h) for $1 \mathrm{~h}$, followed by treatment with $100 \mu \mathrm{M}$ BPA or vehicle for $8 \mathrm{~h}$. $\mathbf{g}$ mHypoA- were treated for 4 or $8 \mathrm{~h}$ to determine binding of ATF3 to the ATF3 promoter. The level of ATF3 or IgG binding to each region was assayed using qRT-PCR. Data are expressed as mean \pm SEM, and statistical significance at each site was determined using one-way ANOVA followed by the Bonferroni post hoc test $(\mathbf{b}, \mathbf{c}) .{ }^{*} p<0.05$. BPA, bisphenol A; ChIP, chromatin immunoprecipitation; qRTPCR, quantitative reverse transcriptase polymerase chain reaction.

59 cells serum starved for $1 \mathrm{~h}$ and treated with $100 \mu \mathrm{M}$ BPA or vehicle for 5 min. i mHypoA-59 cells treated with $100 \mu \mathrm{M}$ BPA or vehicle for $8 \mathrm{~h}$. j mHypoA-59 cells treated with $500 \mu \mathrm{M}$ AICAR (AMPK activator) for $9 \mathrm{~h}$. Gene expression was analyzed using qRT-PCR. Protein levels were analyzed using Western blotting and representative blots from one experimental replicate are shown. Data are expressed as mean \pm SEM, and statistical significance was determined using two-way ANOVA followed by Tukey multiple comparison test $(\mathbf{a}-\mathbf{c}, \mathbf{f}, \mathbf{h})$ or by Bonferroni post hoc test $(\mathbf{d}, \mathbf{e})$ or using the Student $t$ test $(\mathbf{g}, \mathbf{i}, \mathbf{j})$. Vehicle versus BPA/ $\mathrm{H}_{2} \mathrm{O}$ versus AICAR: ${ }^{*} p<0.05,{ }^{* *} p<0.01,{ }^{* * *} p<0.001,{ }^{* * * *} p<0.0001$; $\mathrm{NC}$ versus siRNA/ $\mathrm{H}_{2} \mathrm{O} / \mathrm{DMSO}$ versus inhibitor: ${ }^{\#} p<0.05$, ${ }^{\# \#} p<$ 0.01 , ${ }^{\# \# \#} p<0.001$, ${ }^{\# \# \#} p<0.0001$; interaction: ${ }^{++++} p<0.0001$. ActD, actinomycin D; AICAR, 5-aminoimidazole-4-carboxamide ribonucleotide; BPA, bisphenol A; DMSO, dimethyl sulfoxide; ER, endoplasmic reticulum; ns, not significant.

(For figure see next page.) 
with BPA (Fig. 5f, h). Finally, the energy sensor AMPK can upregulate ATF3 [35]. Remarkably, BPA increased AMPK phosphorylation at $8 \mathrm{~h}$ in the mHypoA-59 cells (Fig. 5i), and AMPK activation using AICAR increased Agrp expression, pointing to a potential molecular link between BPA, ATF3, and Agrp.
ATF3 Is Also Involved in the BPA-Mediated Increase in Npy Expression

Given that ATF3 plays a crucial role in regulating BPAinduced Agrp expression, we questioned whether it affects the expression of the other major orexigenic neuropeptide in the arcuate nucleus of the hypothalamus, $N p y$. We have
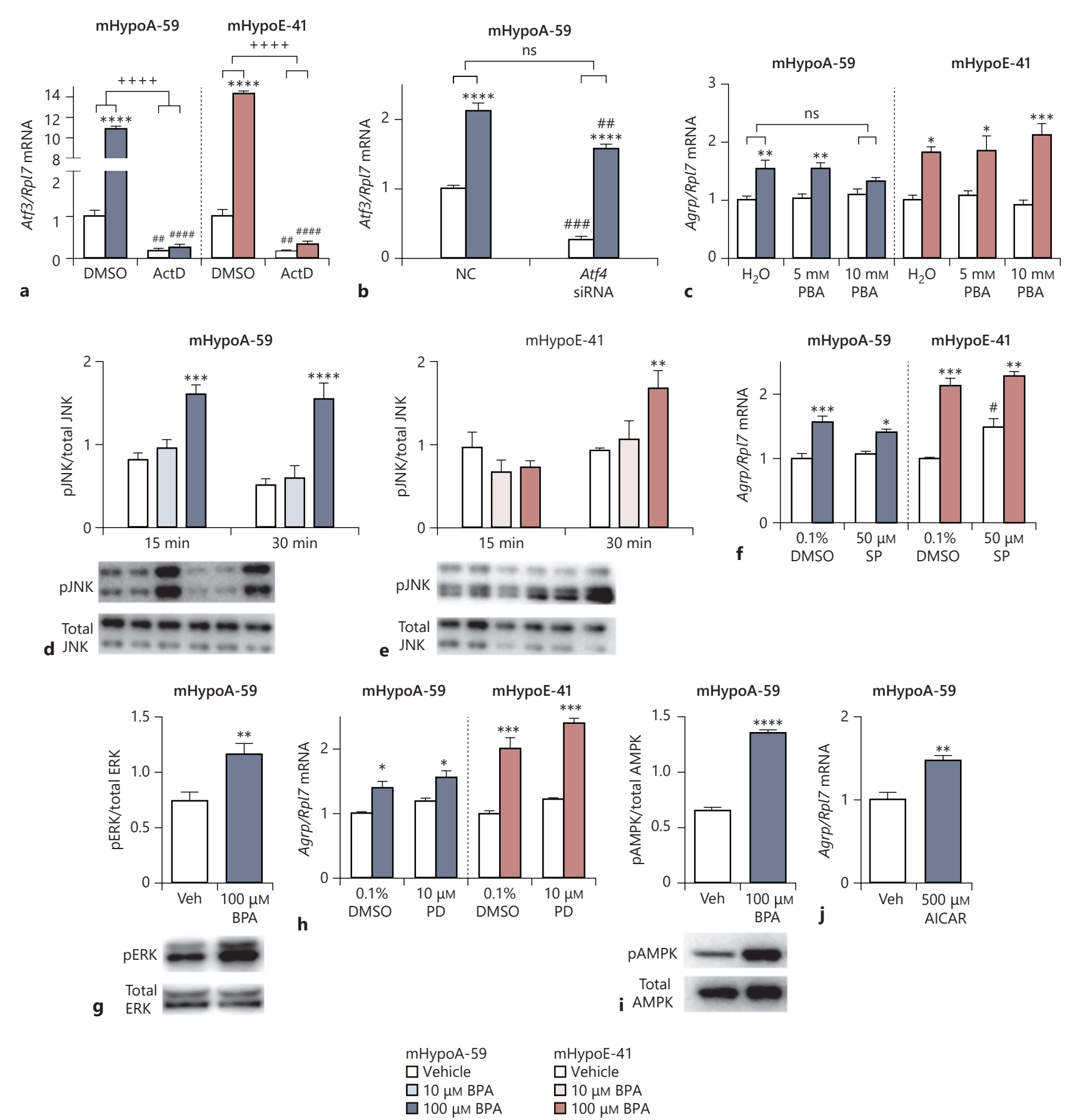


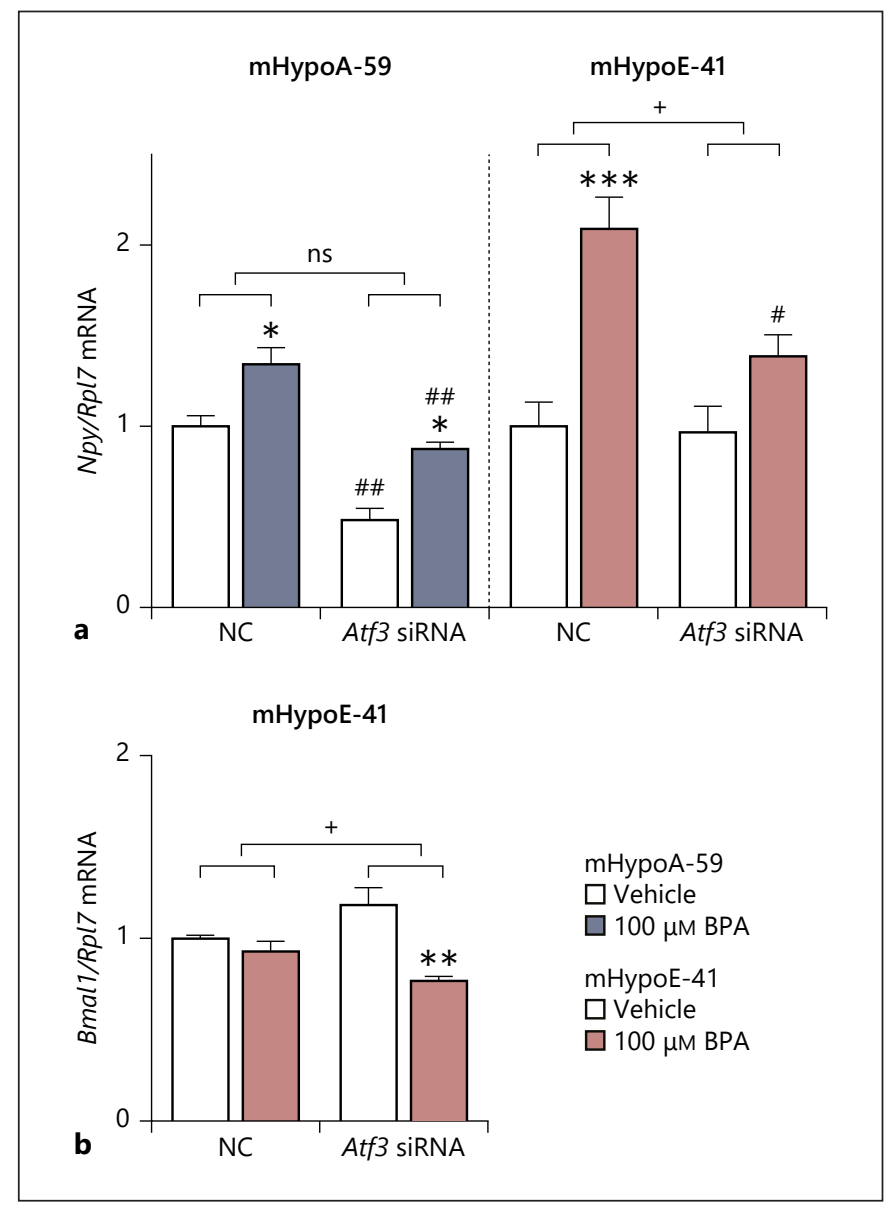

Fig. 6. ATF3 knockdown attenuates the BPA-mediated increase in Npy mRNA expression. mHypoA-59 cells $(\mathbf{a})(n=3)$ or mHypoE-41 cells (a, b) ( $n=6$ for Npy, $n=3$ for Bmal1) transfected with a siRNA duplex targeting Atf 3 or negative control (NC) for $24 \mathrm{~h}$, followed by treatment with $100 \mu \mathrm{M} \mathrm{BPA}$ or vehicle for $8 \mathrm{~h}$. Npy (a) and Bmal1 (b) mRNA expression was measured using qRT-PCR. Data are expressed as mean \pm SEM, and statistical significance was determined using two-way ANOVA followed by Tukey multiple comparison test (a, b). Vehicle versus BPA: ${ }^{*} p<$ $0.05,{ }^{* *} p<0.01,{ }^{* * *} p<0.001$; NC versus siRNA: ${ }^{\#} p<0.05,{ }^{\# \#} p<$ 0.01 ; interaction: ${ }^{+} p<0.05$. BPA, bisphenol A; ns, not significant; qRT-PCR, quantitative reverse transcriptase polymerase chain reaction.

previously shown that BPA-induced Npy upregulation, but not Agrp or Pomc, requires the circadian regulator and transcription factor BMAL1 [15]. Knockdown of ATF3 decreased the basal levels of $N p y$ in both vehicle- and BPA-treated groups in the mHypoA-59 cells (Fig. 6a). In the mHypoE-41 cells, the BPA-induced upregulation of Npy was prevented with ATF3 knockdown (Fig. 6a). Prevention of the Npy increase by BPA occurred with a concurrent decrease in Bmal1 expression when mHypoE-41 cells were treated with BPA in the presence of ATF3
siRNA (Fig. 6b). These results suggest that ATF3, at least in part, also plays a role in the BPA-mediated increase in Npy expression in hypothalamic cells.

\section{Discussion}

The obesogenic effects of BPA have been described with respect to peripheral metabolism $[2,7,36]$; however, how BPA affects the hypothalamic neurons that control whole-body energy homeostasis is far less studied. In fact, BPA has been shown to accumulate in the human hypothalamus [8], highlighting the importance of studying the hypothalamic effects of BPA. Here, we add to the current pool of evidence that BPA affects the hypothalamic NPY/ AgRP neurons by describing that BPA increases de novo transcription of the orexigenic neuropeptide Agrp in hypothalamic neurons through an ATF3-dependent mechanism. We also demonstrate that BPA can alter Agrp expression in not only embryonic-derived but also adultderived neurons using similar mechanisms, underscoring the importance of studying the effects of BPA in adulthood. We further describe that ATF3 is also an important regulator of the BPA-mediated induction of $N p y$, pointing to a common mediator of appetite-increasing effects of BPA in the hypothalamus.

Perinatal exposure to BPA in rodents increases body weight [13], leads to pancreatic dysfunction [37], increases Agrp mRNA levels when combined with a high-fat diet [13], and upregulates AgRP protein levels in neural progenitor cells in vivo and in vitro [12]. In line with this evidence, BPA increased Agrp mRNA expression in four embryonic-derived cell lines. However, BPA increased Agrp expression in adult-derived cell lines and importantly adult-derived hypothalamic primary culture, suggesting that adult neurons are also susceptible to BPAmediated dysregulation of the neuropeptides controlling energy homeostasis, albeit perhaps to a lesser degree, as both the magnitude and the temporal response of increased Agrp were limited in the adult-derived cells. Pubertal or adult exposure to BPA has also been shown to have detrimental consequences in rodent models. For instance, 5-week-old rodents exposed to dietary BPA had increased body weights [7]. Adult-rodent exposure to BPA also led to abnormal insulin production in the pancreas [38], insulin resistance in the muscle [39], and triglyceride accumulation in the liver [40]. Furthermore, urine levels of BPA are correlated with body mass index in children [41] as well as adults [42], suggesting that acute adulthood exposure to BPA is also harmful. Never- 
theless, it is important to note that the timing of exposure during development or in adulthood plays a significant role in the effects of BPA; for example, perinatal exposure starting only at embryonic day 18 and subsequent postnatal exposure up to postnatal day 7 altered neither body weight nor Npy or Agrp expression in the hypothalamus of adult female rats [43].

BPA concentrations were initially thought to be in the low $\mathrm{nM}$ range in human urine samples $(\sim 5 \mathrm{nM})$ [30]. However, new measurement techniques [29] and the fact that BPA accumulates in tissues [44] have indicated that BPA concentrations may be higher than initially thought. Gerona et al. [29] demonstrated that older detection methods largely underestimated the levels of BPA metabolites in human urine samples, and reported mean concentrations to be approximately $230 \mathrm{nM}$, with $\mathrm{BPA}$ as high as $3 \mu \mathrm{M}$ detected in human urine. Our treatment concentration of $100 \mu \mathrm{M}$ was much higher than the reported human concentrations. The relevance of the concentration of BPA and other hormones such as estrogen used in in vitro studies is a primary question. As an example, circulating concentrations of $17 \beta$-estradiol are in the picomolar range [45], while in vitro experiments often require $10-100 \mathrm{nM}(1,000$-fold greater) to detect a significant effect on function [46]. This is in part due to the lipophilic nature of these compounds, which would be appropriate for circulation and fat storage, but the inherent aqueous environment of cell culture experiments may not be conducive to easy access to the neuron. We therefore quantified how much BPA entered the neurons, with the assumption that BPA predominantly affects cells by entering through the plasma membrane rather than via cell surface receptor activation [47]. One exception to this assumption is the membrane-bound estrogen receptor GPER1. Although primarily characterized as residing on the ER membrane [48-50], GPER1 also localizes to the plasma membrane [51], and BPA has been shown to act through this receptor [52]. However, in both mHypoA-59 and mHypoE-41 cells, a GPER1 antagonist, G15, did not block the BPA-mediated induction of Agrp (data not shown), ruling out the involvement of both plasma-membrane and ER-membrane bound GPER1. Besides GPER1, the majority of mechanisms through which BPA affects cells have been intracellular in nature [47]. Based on our quantification, only a fraction of BPA entered the hypothalamic neurons in culture ( $10 \mu \mathrm{M}$ at $4 \mathrm{~h}, 18 \mu \mathrm{M}$ at $24 \mathrm{~h}$ ), suggesting that the exposure concentration was much less than the treatment concentration. Furthermore, the percentage decreased with lower concentrations of BPA, alluding to

Bisphenol A Increases Agrp mRNA through ATF3 the need to use higher concentrations to ensure adequate cellular entry.

ATF3 is a stress-responsive transcription factor of the ATF/CREB family and has been directly linked to the transcriptional upregulation of Agrp in response to low glucose [25]. This effect occurs through binding of ATF3 to FOXO1 and then binding of both to FOXO1-responsive elements on the Agrp promoter [25]. Here, we describe a FOXO1-independent effect of ATF3 since knockdown of FOXO1 did not block the increase in Agrp and ATF3 did not show increased binding to the FOXO1 sites in the Agrp promoter. This FOXO1-independent effect could either occur due to ATF3 homodimer binding, ATF3 dimerizing with another bZIP transcription factor, followed by promoter activation, or through ATF3 altering the expression and/or binding of another transcription factor [28]. The latter may be true for $N p y$. We have previously linked the transcription factor BMAL1 to BPA-induced upregulation of Npy and shown that BPA induces increased BMAL1 binding at the Npy promoter [15]. The mechanism by which BPA increases BMAL1 expression and binding was not elucidated. We show here that when ATF3 is knocked down, BPA leads to a downregulation of Bmall expression in the $\mathrm{mHypoE}-41$ cell line. Early growth response 1 is a primary target of ATF3 [53] and is required for the daily rhythm of Bmall in the suprachiasmatic nucleus of mice [54]. Thus, although direct promoter binding of ATF3 cannot be ruled out, it is possible that ATF3 may, in part, mediate BMAL1 binding to the Npy promoter with BPA exposure.

In terms of Agrp, either or both forms of regulation may be involved. In a study investigating the consensus sequences enriched for ATF3 binding across the human genome, Zhao et al. [28] described that $81 \%$ of ATF3 binding sites contained the ATF:CRE, AP1, or CEBP:ATF consensus sequences. In fact, over half of these binding sites were in distal or enhancer regions far from gene transcriptional start sites [28]. In our study, we determined whether there was increased binding of ATF3 to two putative ATF3 binding sites in the distal regulatory region of Agrp with BPA treatment. Although increased binding with BPA did not occur at either site, there was basal binding at the ATF:CRE site, as compared with IgG in the mHypoA-59 cells. Given that ATF3 knockdown increased Agrp mRNA levels in vehicle-treated mHypoA-59 cells, it is plausible that ATF3 binds and represses Agrp under unstimulated conditions. Similarly, although Agrp expression itself was not studied, knocking out ATF3 in LepRb neurons led to increased body weight in female mice [55], suggesting that ATF3 may contribute to maintaining basal energy homeostasis. 
With low glucose [25] or with BPA exposure, the changing transcription factor pool may result in different factors that then interact with ATF3 and change its transcriptional activity. Interestingly, Zhao et al. [28] found that many genes whose expression was regulated by a stress event, such as DNA damage, were prebound by ATF3, and other transcription factors can then be recruited to these sites. Thus, the idea that prebound ATF3 (promoter bookmarking/ priming) at this site may recruit and bind to alternative transcription factors to increase transcription cannot be ruled out for Agrp. Nevertheless, depending on the binding site, stress-induced elevation of ATF3 can lead to decreased binding of ATF3 to the DNA, and binding of ATF3 activates and represses an approximately equal number of genes, demonstrating the complexity in ATF3-induced regulation [28]. Upon ATF3 knockdown, basal mRNA levels of Agrp and Npy were significantly altered in the mHypoA59 cells but remained unchanged in the mHypoE- 41 cells. This may be due to the presence of specific transcription factors in the adult-derived cell line that interact with ATF3 to control basal levels of Agrp and Npy expression.

Curiously, Stat3 expression was increased with BPA treatment in our experiment and BPA has been shown to induce STAT3 phosphorylation in adipocytes and macrophages $[56,57]$. Both Stat 3 overexpression and phosphorylation would be expected to suppress Agrp expression $[18,58]$, suggesting that in these hypothalamic neurons, BPA increases Agrp independently of STAT3 or that the effects of other transcription factors override the effect of STAT3. In fact, although Stat 3 overexpression directly increases Agrp transcription in in vitro reporter assays [18] and Stat3 knockdown is correlated with an increase in Agrp, STAT3 may not play a significant role in direct Agrp transcription in vivo as initially thought [59]. The Stat 3 induction in hypothalamic neurons in response to BPA may occur secondary to inflammatory cytokine signaling [16], which routinely activates STAT3 $[56,57]$ and occurs independently to Agrp transcription.

Other transcription factors that directly upregulate Agrp that we did not investigate here include the glucocorticoid receptor, brain-specific homeobox (BSX), and Krüppel-like factor 4 (KLF4). BPA is known to bind to and activate several nuclear receptors, including the glucocorticoid receptor [60]. However, the glucocorticoid receptor antagonist RU486 did not block the BPA-mediated increase in Agrp in the mHypoA-59 cells (data not shown). BSX is a transcription factor, highly expressed in the arcuate nucleus of the hypothalamus, and binds to the Agrp promoter adjacent to the FOXO1 binding sites [61, 62 ]. It has also been shown to interact with both FOXO1 and CREB to upregulate Agrp transcription [62]. KLF4 is a zinc finger transcription factor that binds to CACCC element in the Agrp promoter [63]. Interestingly, it has been described to activate transcription of Atf3 in human colorectal cancer cells [64]. Whether BSX and KLF4 are altered with BPA in hypothalamic cells and whether they independently and/or with ATF3 contribute to BPA-mediated Agrp warrants further investigation.

As a stress-responsive transcription factor, ATF3 is activated by a myriad of upstream pathways and kinases. For instance, ER stress induces ATF3, along with other classic ER stress-related factors, such as ATF4 and ATF6 [23]. Belonging to the same family, these have similar consensus sequences for promoter binding. However, the DNA binding profile and gene regulation profile of ATF3 is distinct from ATF4 and ATF6, largely due to its ability to interact with a variety of other transcription factors [28]. This is corroborated by our findings that although BPA induced ER stress, ATF3, ATF4, and ATF6, the BPA-mediated increase in Agrp is only dependent on ATF3. The MAP kinases JNK and ERK were also activated with BPA treatment and are known upstream regulators of ATF3 [34]. However, in our study, the BPA-mediated upregulation of Agrp or Atf3 (data not shown) was not blocked by JNK and ERK pathway inhibition. Interestingly, there was a nonsignificant trend in the mHypoA-59 cells, where the magnitude of upregulation in Agrp was decreased in the presence of the JNK inhibitor and the chemical chaperone PBA, whereas this did not occur in the mHypoE-41 cells. Again, this may allude to the greater vulnerability of the Agrp system in embryonic neurons to BPA treatment as blocking these pathways may, in part, alleviate some of the BPA-induced alterations in the mHypoA-59 neurons.

Examining the mechanisms by which nutrient signals regulate Agrp may give clues as to how BPA may be regulating Agrp. Amino acid deprivation increases Agrp and ATF3 [65]. Amino acid supplementation decreases levels of Agrp in hypothalamic neurons via mTOR activation [20]. mTOR is active in states of high energy, while AMPK activation in the hypothalamus occurs during states of low energy, such as fasting. In fact, constitutively active AMPK has been shown to increase Agrp [66], and ATF3 is a downstream target of AMPK [35]. We therefore evaluated whether BPA leads to AMPK activation and found that BPA increases AMPK phosphorylation and thus activation in mHypoA-59 cells. Furthermore, activation of AMPK using AICAR led to an increase in Agrp mRNA expression. These results suggest that BPA may mimic a state of low energy in hypothalamic neurons, leading to the induction of AMPK, ATF3, and ultimately orexigenic 
Agrp mRNA expression. Future experiments using inhibitors of AMPK activity are required to confirm the relationship between AMPK, ATF3, and Agrp as AMPK can also target other factors, including BSX [67] and KLF4 [68], which can lead to the increase in Agrp.

In addition to increasing food intake, AgRP neurons also act as the main center of actions of the satiety factors insulin and leptin and maintain whole-body glucose homeostasis by suppressing gluconeogenesis [63]. Given that insulin and leptin both act on AgRP neurons to mediate satiety by directly decreasing Agrp transcription, the fact that BPA leads to de novo Agrp transcription may override the effects of such satiety factors. In fact, insulin and leptin resistance have both been described with BPA exposure $[69,70]$.

In conclusion, we describe for the first time that BPA increases de novo transcription of Agrp through an ATF3dependent mechanism in hypothalamic neurons. ATF3 is also, at least in part, involved in the BPA-mediated increase in $N p y$, suggesting a common, targetable mediator to alleviate the orexigenic effects of BPA in the hypothalamus.

\section{Acknowledgement}

We thank all members of the Belsham Lab for technical assistance and helpful discussions.

\section{Statement of Ethics}

All animal procedures were conducted in accordance with the regulations of the Canadian Council on Animal Care and approved by the University of Toronto Animal Care Committee.

\section{Conflict of Interest Statement}

The authors have no conflicts of interest to declare.

\section{Funding Sources}

The authors acknowledge funding from the Canadian Institutes for Health Research and the Canada Foundation for Innovation and Canada Research Chairs Program (D.D. Belsham). N. Loganathan and E.K. McIlwraith were supported by the Natural Sciences and Engineering Research Council and the Banting \& Best Diabetes Centre. E.K. McIlwraith was also supported by the Ontario Graduate Studentship.

\section{Author Contributions}

N. Loganathan and E.K. McIlwraith designed and performed the experiments and analyzed the data. N. Loganathan wrote the first draft of the manuscript. D.D. Belsham conceived the study, obtained funding, designed the study, and interpreted the data. All authors edited the manuscript and read and approved the final manuscript.

\section{References}

1 Marraudino M, Bonaldo B, Farinetti A, Panzica G, Ponti G, Gotti S. Metabolism Disrupting Chemicals and Alteration of Neuroendocrine Circuits Controlling Food Intake and Energy Metabolism. Front Endocrinol (Lausanne). 2019 Jan;9:766.

2 Diamanti-Kandarakis E, Bourguignon JP, Giudice LC, Hauser R, Prins GS, Soto AM, et al. Endocrine-disrupting chemicals: an Endocrine Society scientific statement. Endocr Rev. 2009 Jun;30(4):293-342.

3 Rancière F, Lyons JG, Loh VHY, Botton J, Galloway T, Wang T, et al. Bisphenol A and the risk of cardiometabolic disorders: a systematic review with meta-analysis of the epidemiological evidence. Environ Health. 2015 May; 14:46.

4 Stats Canada. Bisphenol A concentrations in Canadians, 2012 and 2013. 2013. https:// www150.statcan.gc.ca/n1/en/catalogue/82625-X201500114208.

5 Hong SH, Sung YA, Hong YS, Ha E, Jeong K, Chung $\mathrm{H}$, et al. Urinary bisphenol A is associated with insulin resistance and obesity in reproductive-aged women. Clin Endocrinol (Oxf). 2017 Apr;86(4):506-12.
6 Provvisiero DP, Pivonello C, Muscogiuri G, Negri M, de Angelis C, Simeoli C, et al. Influence of Bisphenol A on Type 2 Diabetes Mellitus. Int J Environ Res Public Health. 2016 Oct;13(10):E989.

7 Yang M, Chen M, Wang J, Xu M, Sun J, Ding $\mathrm{L}$, et al. Bisphenol A promotes adiposity and inflammation in a nonmonotonic dose-response way in 5-week-old male and female C57BL/6J mice fed a low-calorie diet. Endocrinology. 2016 Jun;157(6):2333-45.

8 Charisiadis $\mathrm{P}$, Andrianou XD, van der Meer TP, den Dunnen WF, Swaab DF, Wolffenbuttel $\mathrm{BH}$, et al. Possible Obesogenic Effects of Bisphenols Accumulation in the Human Brain. Sci Rep. 2018 May;8(1):8186.

9 Boucher JG, Boudreau A, Atlas E. Bisphenol A induces differentiation of human preadipocytes in the absence of glucocorticoid and is inhibited by an estrogen-receptor antagonist. Nutr Diabetes. 2014 Jan;4(1):e102.

10 Wang J, Sun B, Hou M, Pan X, Li X. The environmental obesogen bisphenol A promotes adipogenesis by increasing the amount of $11 \beta$-hydroxysteroid dehydrogenase type 1 in the adipose tissue of children. Int J Obes (Lond). 2013 Jul;37(7):999-1005.
11 Arora S, Anubhuti. Role of neuropeptides in appetite regulation and obesity - a review. Neuropeptides. 2006 Dec;40(6):375-401.

12 Desai M, Ferrini MG, Han G, Jellyman JK, Ross MG. In vivo maternal and in vitro BPA exposure effects on hypothalamic neurogenesis and appetite regulators. Environ Res. 2018 Jul;164:45-52.

13 MacKay H, Patterson ZR, Khazall R, Patel S, Tsirlin D, Abizaid A. Organizational effects of perinatal exposure to bisphenol-A and diethylstilbestrol on arcuate nucleus circuitry controlling food intake and energy expenditure in male and female CD-1 mice. Endocrinology. 2013 Apr; 154(4):1465-75.

14 Hagan MM, Rushing PA, Pritchard LM, Schwartz MW, Strack AM, Van Der Ploeg LH, et al. Long-term orexigenic effects of AgRP(83-132) involve mechanisms other than melanocortin receptor blockade. Am J Physiol Regul Integr Comp Physiol. 2000 Jul;279(1):R47-52.

15 Loganathan N, Salehi A, Chalmers JA, Belsham DD. Bisphenol A Alters Bmal1, Per2, and Rev-Erba mRNA and Requires Bmall to Increase Neuropeptide Y Expression in Hypothalamic Neurons. Endocrinology. 2019 Jan;160(1):181-92. 
16 Salehi A, Loganathan N, Belsham DD. Bisphenol A induces Pomc gene expression through neuroinflammatory and PPARgamma nuclear receptor-mediated mechanisms in POMCexpressing hypothalamic neuronal models. Mol Cell Endocrinol. 2019 Jan;479:12-19.

17 Mayer CM, Belsham DD. Insulin directly regulates NPY and AgRP gene expression via the MAPK MEK/ERK signal transduction pathway in mHypoE-46 hypothalamic neurons. Mol Cell Endocrinol. 2009 Aug;307(1-2):99108.

18 Kitamura T, Feng Y, Kitamura YI, Chua SC $\mathrm{Jr}, \mathrm{Xu} \mathrm{AW}$, Barsh GS, et al. Forkhead protein FoxO1 mediates Agrp-dependent effects of leptin on food intake. Nat Med. 2006 May; 12(5):534-40.

19 Chalmers JA, Jang JJ, Belsham DD. Glucose sensing mechanisms in hypothalamic cell models: glucose inhibition of AgRP synthesis and secretion. Mol Cell Endocrinol. 2014 Jan; 382(1):262-70

20 Morrison CD, Xi X, White CL, Ye J, Martin RJ. Amino acids inhibit Agrp gene expression via an mTOR-dependent mechanism. Am J Physiol Endocrinol Metab. 2007 Jul; 293(1):E165-71.

21 Kaelin CB, Xu AW, Lu XY, Barsh GS. Transcriptional regulation of agouti-related protein (Agrp) in transgenic mice. Endocrinology. 2004 Dec;145(12):5798-806.

22 Asahi J, Kamo H, Baba R, Doi Y, Yamashita A, Murakami D, et al. Bisphenol A induces endoplasmic reticulum stress-associated apoptosis in mouse non-parenchymal hepatocytes. Life Sci. 2010 Sep;87(13-14):431-8.

23 Iurlaro R, Muñoz-Pinedo C. Cell death induced by endoplasmic reticulum stress. FEBS J. 2016 Jul;283(14):2640-52.

24 Park S, Jang A, Bouret SG. Maternal obesityinduced endoplasmic reticulum stress causes metabolic alterations and abnormal hypothalamic development in the offspring. PLoS Biol. 2020 Mar;18(3):e3000296.

25 Lee YS, Sasaki T, Kobayashi M, Kikuchi O, Kim HJ, Yokota-Hashimoto H, et al. Hypothalamic ATF3 is involved in regulating glucose and energy metabolism in mice. Diabetologia. 2013 Jun;56(6):1383-93.

26 Belsham DD, Fick LJ, Dalvi PS, Centeno ML, Chalmers JA, Lee PK, et al. Ciliary neurotrophic factor recruitment of glucagon-like peptide-1 mediates neurogenesis, allowing immortalization of adult murine hypothalamic neurons. FASEB J. 2009 Dec;23(12): 4256-65.

27 Belsham DD, Cai F, Cui H, Smukler SR, Salapatek AM, Shkreta L. Generation of a phenotypic array of hypothalamic neuronal cell models to study complex neuroendocrine disorders. Endocrinology. 2004 Jan;145(1):393400.

28 Zhao J, Li X, Guo M, Yu J, Yan C. The common stress responsive transcription factor ATF3 binds genomic sites enriched with p300 and $\mathrm{H} 3 \mathrm{~K} 27 \mathrm{ac}$ for transcriptional regulation. BMC Genomics. 2016 May;17(1):335.
29 Gerona R, Vom Saal FS, Hunt PA. BPA: have flawed analytical techniques compromised risk assessments? Lancet Diabetes Endocrinol. 2020 Jan;8(1):11-3.

30 Calafat AM, Kuklenyik Z, Reidy JA, Caudill SP, Ekong J, Needham LL. Urinary concentrations of bisphenol A and 4-nonylphenol in a human reference population. Environ Health Perspect. 2005 Apr;113(4):391-5.

31 Li JH, Zhou BX, Cai WM. The Solubility Behavior of Bisphenol A in the Presence of Surfactants. J Chem Eng Data. 2007;52(6):25113.

32 Mayer SI, Dexheimer V, Nishida E, Kitajima $S$, Thiel G. Expression of the transcriptional repressor ATF3 in gonadotrophs is regulated by Egr-1, CREB, and ATF2 after gonadotropin-releasing hormone receptor stimulation. Endocrinology. 2008 Dec;149(12):6311-25.

33 Mungrue IN, Pagnon J, Kohannim O, Gargalovic PS, Lusis AJ. CHAC1/MGC4504 is a novel proapoptotic component of the unfolded protein response, downstream of the ATF4-ATF3-CHOP cascade. J Immunol. 2009 Jan;182(1):466-76.

$34 \mathrm{Lu} \mathrm{D}$, Chen J, Hai T. The regulation of ATF3 gene expression by mitogen-activated protein kinases. Biochem J. 2007 Jan;401(2):559-67.

35 Liu X, Wang N, Fan S, Zheng X, Yang Y, Zhu $Y$, et al. The citrus flavonoid naringenin confers protection in a murine endotoxaemia model through AMPK-ATF3-dependent negative regulation of the TLR4 signalling pathway. Sci Rep. 2016 Dec;6(1):39735.

36 Sargis RM, Johnson DN, Choudhury RA, Brady MJ. Environmental endocrine disruptors promote adipogenesis in the 3T3-L1 cell line through glucocorticoid receptor activation. Obesity (Silver Spring). 2010 Jul;18(7):1283-8.

37 Wei J, Lin Y, Li Y, Ying C, Chen J, Song L, et al. Perinatal exposure to bisphenol A at reference dose predisposes offspring to metabolic syndrome in adult rats on a high-fat diet. Endocrinology. 2011 Aug;152(8):3049-61.

38 Ropero AB, Alonso-Magdalena P, GarcíaGarcía E, Ripoll C, Fuentes E, Nadal A. Bisphenol-A disruption of the endocrine pancreas and blood glucose homeostasis. Int $\mathrm{J}$ Androl. 2008 Apr;31(2):194-200.

39 Batista TM, Alonso-Magdalena P, Vieira E, Amaral ME, Cederroth CR, Nef S, et al. Shortterm treatment with bisphenol-A leads to metabolic abnormalities in adult male mice. PLoS One. 2012;7(3):e33814.

40 Marmugi A, Ducheix S, Lasserre F, Polizzi A, Paris A, Priymenko N, et al. Low doses of bisphenol A induce gene expression related to lipid synthesis and trigger triglyceride accumulation in adult mouse liver. Hepatology. 2012 Feb;55(2):395-407.

41 Kim KY, Lee E, Kim Y. The Association between Bisphenol A Exposure and Obesity in Children - A Systematic Review with MetaAnalysis. Int J Environ Res Public Health. 2019 Jul;16(14):E2521.

42 Do MT, Chang VC, Mendez MA, de Groh M. Urinary bisphenol A and obesity in adults: re- sults from the Canadian Health Measures Survey. Health Promot Chronic Dis Prev Can. 2017 Dec;37(12):403-12.

43 Roepke TA, Yang JA, Yasrebi A, Mamounis KJ, Oruc E, Zama AM, et al. Regulation of arcuate genes by developmental exposures to endocrine-disrupting compounds in female rats. Reprod Toxicol. 2016 Jul;62:18-26.

44 Stahlhut RW, Welshons WV, Swan SH. Bisphenol A data in NHANES suggest longer than expected half-life, substantial nonfood exposure, or both. Environ Health Perspect. 2009 May;117(5):784-9.

45 Depypere HT, Bolca S, Bracke M, Delanghe J, Comhaire F, Blondeel P. The serum estradiol concentration is the main determinant of the estradiol concentration in normal breast tissue. Maturitas. 2015 May;81(1):42-5.

46 Titolo D, Cai F, Belsham DD. Coordinate regulation of neuropeptide $\mathrm{Y}$ and agouti-related peptide gene expression by estrogen depends on the ratio of estrogen receptor (ER) alpha to ERbeta in clonal hypothalamic neurons. $\mathrm{Mol}$ Endocrinol. 2006 Sep;20(9):2080-92.

47 Acconcia F, Pallottini V, Marino M. Molecular Mechanisms of Action of BPA. Dose Response. 2015 Oct;13(4):1559325815610582.

48 Otto C, Rohde-Schulz B, Schwarz G, Fuchs I, Klewer M, Brittain D, et al. G protein-coupled receptor 30 localizes to the endoplasmic reticulum and is not activated by estradiol. Endocrinology. 2008 Oct;149(10):4846-56.

49 Revankar CM, Cimino DF, Sklar LA, Arterburn JB, Prossnitz ER. A transmembrane intracellular estrogen receptor mediates rapid cell signaling. Science. 2005 Mar;307(5715): 1625-30.

50 Revankar CM, Mitchell HD, Field AS, Burai $\mathrm{R}$, Corona C, Ramesh C, et al. Synthetic estrogen derivatives demonstrate the functionality of intracellular GPR30. ACS Chem Biol. 2007 Aug;2(8):536-44.

51 Funakoshi T, Yanai A, Shinoda K, Kawano MM, Mizukami Y. G protein-coupled receptor 30 is an estrogen receptor in the plasma membrane. Biochem Biophys Res Commun. 2006 Aug;346(3):904-10.

52 Dong S, Terasaka S, Kiyama R. Bisphenol A induces a rapid activation of Erk1/2 through GPR30 in human breast cancer cells. Environ Pollut. 2011 Jan;159(1):212-8.

53 Giraldo A, Barrett OP, Tindall MJ, Fuller SJ, Amirak E, Bhattacharya BS, et al. Feedback regulation by Atf3 in the endothelin-1-responsive transcriptome of cardiomyocytes: Egr1 is a principal Atf3 target. Biochem J. 2012 Jun;444(2):343-55.

54 Riedel CS, Georg B, Jørgensen HL, Hannibal J, Fahrenkrug J. Mice Lacking EGR1 Have Impaired Clock Gene (BMAL1) Oscillation, Locomotor Activity, and Body Temperature. J Mol Neurosci. 2018 Jan;64(1):9-19.

55 Allison MB, Pan W, MacKenzie A, Patterson C, Shah K, Barnes T, et al. Defining the Transcriptional Targets of Leptin Reveals a Role for Atf3 in Leptin Action. Diabetes. 2018 Jun; 67(6):1093-104. 
56 Valentino R, D’Esposito V, Passaretti F, Liotti A, Cabaro S, Longo M, et al. BisphenolA impairs insulin action and up-regulates inflammatory pathways in human subcutaneous adipocytes and 3T3-L1 cells. PLoS One. 2013 Dec;8(12):e82099.

57 Huang FM, Chang YC, Lee SS, Yang ML, Kuan YH. Expression of pro-inflammatory cytokines and mediators induced by Bisphenol A via ERK-NFkB and JAK1/2-STAT3 pathways in macrophages. Environ Toxicol. 2019 Apr;34(4):486-94.

58 Varela L, Horvath TL. Leptin and insulin pathways in POMC and AgRP neurons that modulate energy balance and glucose homeostasis. EMBO Rep. 2012 Dec;13(12): 1079-86.

59 Mesaros A, Koralov SB, Rother E, Wunderlich FT, Ernst MB, Barsh GS, et al. Activation of Stat 3 signaling in AgRP neurons promotes locomotor activity. Cell Metab. 2008 Mar;7(3):236-48.

60 Prasanth GK, Divya LM, Sadasivan C. Bisphenol-A can bind to human glucocorticoid receptor as an agonist: an in silico study. J Appl Toxicol. 2010 Nov;30(8):769-74.

61 Lee B, Kim SG, Kim J, Choi KY, Lee S, Lee SK, et al. Brain-specific homeobox factor as a tar- get selector for glucocorticoid receptor in energy balance. Mol Cell Biol. 2013 Jul;33(14): $2650-8$.

62 Sakkou M, Wiedmer P, Anlag K, Hamm A, Seuntjens E, Ettwiller L, et al. A role for brainspecific homeobox factor Bsx in the control of hyperphagia and locomotory behavior. Cell Metab. 2007 Jun;5(6):450-63.

63 Ilnytska O, Stütz AM, Park-York M, York DA, Ribnicky DM, Zuberi A, et al. Molecular mechanisms for activation of the agouti-related protein and stimulation of appetite. Diabetes. $2011 \mathrm{Jan} ; 60(1): 97-106$.

64 Whitlock NC, Bahn JH, Lee SH, Eling TE, Baek SJ. Resveratrol-induced apoptosis is mediated by early growth response-1, Krüppellike factor 4 , and activating transcription factor 3. Cancer Prev Res (Phila). 2011 Jan;4(1): $116-27$.

65 Pan YX, Chen H, Thiaville MM, Kilberg MS. Activation of the ATF3 gene through a co-ordinated amino acid-sensing response programme that controls transcriptional regulation of responsive genes following amino acid limitation. Biochem J. 2007 Jan;401(1):299307.

66 Minokoshi Y, Alquier T, Furukawa N, Kim YB, Lee A, Xue B, et al. AMP-kinase regulates food intake by responding to hormonal and nutrient signals in the hypothalamus. Nature. 2004 Apr;428(6982):569-74.

67 Lage R, Vázquez MJ, Varela L, Saha AK, Vidal-Puig A, Nogueiras R, et al. Ghrelin effects on neuropeptides in the rat hypothalamus depend on fatty acid metabolism actions on BSX but not on gender. FASEB J. 2010 Aug;24(8): 2670-9.

68 Sunaga H, Matsui H, Anjo S, Syamsunarno MR, Koitabashi N, Iso T, et al. Elongation of Long-Chain Fatty Acid Family Member 6 (Elovl6)-Driven Fatty Acid Metabolism Regulates Vascular Smooth Muscle Cell Phenotype Through AMP-Activated Protein Kinase/Krüppel-Like Factor 4 (AMPK/KLF4) Signaling. J Am Heart Assoc. 2016 Nov; 5(12): 0004014.

69 Fang F, Chen D, Yu P, Qian W, Zhou J, Liu J, et al. Effects of Bisphenol A on glucose homeostasis and brain insulin signaling pathways in male mice. Gen Comp Endocrinol. 2015 Feb;212:44-50.

70 MacKay H, Patterson ZR, Abizaid A. Perinatal Exposure to Low-Dose Bisphenol-A Disrupts the Structural and Functional Development of the Hypothalamic Feeding Circuitry. Endocrinology. 2017 Apr;158(4):768-77. 